\title{
Synthesis, characterization and evaluation of stearyl acrylate-co-behenyl acrylate copolymer as a pour point depressant of waxy crude oil
}

\author{
Basem Elarbe $^{1} \cdot$ Ibrahim Elganidi $^{1} \cdot$ Norida Ridzuan $^{1}{ }^{10} \cdot$ Kamal Yusoh $^{1} \cdot$ Norhayati Abdullah $^{1} \cdot$ Shamala Vijayakumar $^{1}$
}

Received: 27 July 2021 / Accepted: 27 November 2021 / Published online: 8 December 2021

(c) The Author(s) 2021

\begin{abstract}
Pour point depressant (PPD) has the competitive advantage of lowering the temperature of the wax appearance (WAT) and crude oil viscosity. In this paper, a novel PPD of poly stearyl acrylate-co-behenyl acrylate (SA-co-BA) in various mass ratios (1:1, 2:1, 3:1, 1:2 and 1:3) was effectively synthesized by solution radical polymerization method, and characterized by fourier transform infrared FTIR, proton nuclear magnetic resonance NMR, x-ray diffraction XRD and scanning electron microscopy SEM. The SA-co-BA PPD was evaluated on Malaysian crude oil via the pour point, the rheological and cold finger analysis to prevent the wax deposition at low temperature and improve flowability. The findings showed that the mass ratio (1:1) at $1000 \mathrm{ppm}$ has a positive effect on the pour point depression from 11 to $2{ }^{\circ} \mathrm{C}$. It was investigated from the rheological measurement that the viscosity of crude oil increases as the temperature decreases. Whereas, the viscosity decreases as the shear rate increases and as shear rate increases, shear stress increases. The flowability performance of the crude by the mass ratio of $1: 1$ at 1000 of the SA-co-BA concentrations have improved by $89.76 \%$. The highest paraffin inhibition efficiency PIE of wax deposited was obtained at $1: 1$ of the mass ratio by $44.14 \%$, indicating the smallest amount of wax is formed. This finding is interestingly attributed to the acrylate groups that have a long alkyl chain. Thus, SA-co-BA copolymer was demonstrated to be an appreciable pour point depressant that can prevent the wax deposition at low temperature and increasing the flowability of Malaysian crude oil.
\end{abstract}

Keywords Cold finger $\cdot$ SA-co-BA copolymer $\cdot$ Pour point $\cdot$ Viscosity $\cdot$ Wax deposition

\section{Introduction}

In recent decades, world energy consumption and crude oil demand have increased dramatically, prompting mining and manufacturing companies to extend their processes into cold regions such as deep waters offshore. These offshore activities have enhanced problems with flow assurance faced through the production and transportation of crude oil pipelines (Sharma et al. 2021). Crude oil is important in countries that have a high demand for fuel, whether for manufacturing use, mobilization of energy or transport. Therefore, crude oil is a critical field, particularly in industrial

Norida Ridzuan

norida@ump.edu.my

1 Faculty of Chemical and Process Engineering Technology, Universiti Malaysia Pahang, 26300 Gambang, Pahang, Malaysia applications, where it is used to contribute to energy production. (Souas et al. 2020). The fluid is comprised of a comprehensive and complicated variety of hydrocarbon materials, consisting primarily of paraffin, aromatic hydrocarbons, resins and asphalt. (Al-Sabagh et al. 2017). In reservoirs at high temperature $\left(70-150{ }^{\circ} \mathrm{C}\right)$, crystallization of wax does not occur because of high temperature, which is sufficient to ensure that the kinds of paraffin remain in the solution (Xu et al. 2013).

In general, if the temperature of fuel is reduced to its wax appearance temperature (WAT), the wax crystals begin to precipitate from fluid and start to aggregate into the internal surface of the pipelines, thereby reducing oil flow and potentially blocking the channel (Yang et al. 2017). These wax crystal precipitates appear to be platelet or needleshaped and tend to agglomerate, leading to the growth of three-dimensional pipeline networks, causing the flowability of crude oil to decrease (Yao et al. 2018). This issue has become more dangerous for deep-water offshore wells 
wherever the temperature of the sea bed is $5{ }^{\circ} \mathrm{C}$ or less (Xu et al. 2013). Thereby, accumulation of wax is the main issue in production, separation process, refining and transportation of fluid due to low temperature (Sivakumar et al. 2018). Due to a decrease in fluid pressure and temperature, the growth of wax crystals in the fluid quickens as it exits the reservoir and flows through the pipeline (Sivakumar et al. 2018). Because of this, the viscosity of fluid rises with the reduction in temperature, resulting in a decrease in flowability. This problem might stop the flow of fuel in serious situations. In addition, deposition of wax is one of the issues described earlier that is widespread and poses a severe operational issue; it alters the rheological characteristic of fuel, causing it to flow more slowly. Wax deposition in oil pipelines can narrow the flow channel, raise the resistance and reduce the flowability (Geest et al. 2021). The cost of blocked pipeline remediation in depths of the ocean is around $\$ 1$ million/mile, which is stated via the U.S Energy Sector (Senra et al. 2008; Xu et al. 2013). Crude oil in the Petrochina Liaohe oil field has a high content of paraffin, which causes it to have a high pour point and viscosity, which is complex to be exploited. This raises issues of the excessive cost of oil recovery and transportation (Xu et al. 2013).

To overcome of these issues, several treatments have been employed to address issues of fluidity at cold areas to minimize wax crystal accumulation such as mechanical, thermal and chemical. In the field of oil and gas production, the most familiar and cheapest treatment is to inject pour point depressant (PPD) into the crude oil. PPD is one of the chemical treatments that is generally utilized to inhibit or mitigate the wax deposition and act to increase the crude oil flowability during transportation. The PPD is also known either as wax crystal modifier or flow improver, which are compounds of polymeric that have formed by a series of hydrocarbons that supply the interaction between the wax inhibitor PPD and wax paraffin and act to change the morphology of crystal. Due to the significant role of PPDs in oil production and transportation, several PPDs were synthesized and evaluated on waxy crude oil, such as copolymer of ethylene-co-vinyl acetate (EVA) (Machado et al. 2001; Tu et al. 2017), poly of octadecyl acrylate (POA) polymer (Handayani et al. 2019; Yang et al. 2018; Yang et al. 2015a, b; Zhu et al. 2004), poly of alkyl acrylate (Feng et al. 2014; Litvinets et al. 2016), poly of dodecyl methacrylate-co- vinyl acetate (Ghosh et al. 2017), poly of glycidyl methacrylateco- octadecyl methacrylate (Goswami et al. 2019), poly of methacrylate-co-maleic anhydride (Xu et al. 2018) poly of methylsilsesquioxane (PMSQ) microsphere (Yang et al. 2017), poly of maleic anhydride - co- alkyl linoleate (Soliman et al. 2018), terpolymer of alkyl acrylate-co-vinyl acetate-co-maleic anhydride (Feng et al. 2014) poly of stearyl acrylate-co-behenyl acrylate (SABA) copolymer (Elarbe et al. 2021), poly of fatty esters- $\mathrm{co}$-succinic anhydride (Deka et al. 2020), poly of ethylene-co-butene with nano-aluminum oxide blend (Odutola and Idemili 2020) poly of benzyl methacrylate-co-methacrylate (Xie et al. 2019) and terpolymer of benhely acrylate- $\mathrm{co}$-stearyl methacrylate-co-maleic anhydride (Elganidi et al. 2020). These studies have a strong influence on the viscosity reduction which can improve the performance of the flowability and inhibit the deposition of wax. Although several studies have been investigated in the previous literature (Chi et al. 2016; Yang et al. 2015a, b), the exact mechanism by which wax inhibitor's function is still unclear. As a result, various experimental approaches are employed.

Elganidi et al. (2020) studied the influence of benhely acrylate-co-stearyl methacrylate-co-maleic anhydride terpolymer as a new PPD to increase the flowability of the Malaysian fluid. The experimental results exhibited that terpolymer can decrease the fluid viscosity from $7.2 \mathrm{cp}$ to 3.2 cp using $1500 \mathrm{ppm}$ at $30^{\circ} \mathrm{C}$ (Elganidi et al. 2020). Barasha Deka et al. (2020) synthesized and evaluated the effect of poly of dodecyl linoleate-co-succinic anhydride as copolymer and poly of dodecyl ricinoleate-co-succinic anhydride as PPDs on WAT, the pour point, gelation point and crude oil viscosity at $1250 \mathrm{ppm}$ and $750 \mathrm{ppm}$, respectively. The results displayed that the PPDs have decreased WAT, the pour point, gelation point and crude oil viscosity. In addition, the PPDs improved the flow through the tubing by significantly decreasing the wax deposition (Deka et al. 2020). Subramanie et al. (2020) have studied the impact of MA and EVA as wax inhibitors PPDs blended with Sodium cloisite $\mathrm{Na}^{+}$and without it on the fluid viscosity of Malaysian at different ranges of shear rates and temperatures. The finding exhibited that MA and EVA were capable of reducing the crude oil viscosity by $86.4 \%$ and $88.0 \%$, respectively, while the addition of Sodium cloisite $\mathrm{Na}^{+}$to both MA and EVA reduced the viscosity by about $89.2 \%$ and $94 \%$, respectively (Subramanie et al. 2020). Odutola and Idemili (2020) studied the impact of different concentrations of Poly (ethylene-co-butene) (PEB) blend with nanoparticles of aluminum oxide $\left(\mathrm{Al}_{2} \mathrm{O}_{3}\right)$ at $100 \mathrm{ppm}$ of concentration in Niger delta crude oil. The results revealed that PEB copolymer at $2000 \mathrm{ppm}$ combined with aluminum oxide at $100 \mathrm{ppm}$ demonstrated the highest performance for offshore applications with viscosity reductions of $77.9 \%$ at $10{ }^{\circ} \mathrm{C}$ and $73.7 \%$ at $15^{\circ} \mathrm{C}$. (Odutola and Idemili 2020). Yang et al. (2015a, b) have been examined the effect of poly octadecyl acrylate as polymer (POA) combination with the $\mathrm{SiO}_{2}$ nanoparticle on the fluid properties. The gelation point was noted to decrease gradually as the concentration of POA is increased. However, it revealed that a small dose of POA blended with nanosilica had a greater impact on the fluid rheology than using only polymers and exhibited the greatest results at $100 \mathrm{ppm}$. Fengfei Chen et al. (2020) investigated the effect of copolymer (maleic anhydride-co-methyl benzyl acrylate) 
on the cool flow characteristic of fuel. PPD revealed the maximum significant reduction on the SP and CFPP by $8{ }^{\circ} \mathrm{C}$ at $500 \mathrm{ppm}$. Consequently, the synthesized PPD copolymer was the most effective PPD of fuels (Chen et al. 2020). New pour point depressant PPD was synthesized to mitigate this issue. This technique has a considerable influence on the viscosity reductions and increases crude oil flowability through transportation. The motivation for choosing the monomers used in this work was to take advantage of specific features for each monomer. These two monomers have integrated a new-fangled copolymer that other wax inhibition scientists have not yet invented. In addition, the current research's motivation is to synthesize a new pour point depressant (SA-co-BA) copolymer, because to the best of our knowledge, no study of this nature has been published previously.

In the present work, poly of stearyl acrylate-co-behenyl acrylate (SA-co-BA) copolymer was synthesized at five various mass ratios as novel PPD using free-radical polymerization, characterized by GPC, FTIR, ${ }^{1} \mathrm{HNMR}$, SEM and XRD, and SA-co-BA PPD has been evaluated on waxy crude oil via the pour point, the rheological and cold finger analysis to prevent the wax deposition at low temperature and improve flowability of Malaysian fluid by reducing the viscosity, pour point and wax deposition.

\section{Methodology}

\section{Materials}

Stearyl acrylate $97 \%$, behenyl acrylate $95 \%$, toluene $99 \%$ and benzoyl peroxide 99\% obtained from Sigma Aldrich. Samples of fluid were kindly supplied by the refinery of PETRONAS from Kerteh, Terengganu, Malaysia.

\section{Description of physicochemical properties of Malaysian fluid}

In Table 1, the physicochemical properties of Malaysian fluid were mentioned. In the laboratory, pour point, viscosity, wax appearance temperature (WAT) and API gravity were tested using Koehler's Cloud point bath, a Brookfield

Table 1 Physicochemical properties of Malaysian fluid sample

\begin{tabular}{lll}
\hline Characteristics of fluid & Value & Test instruments \\
\hline Viscosity mPa.s at $30{ }^{\circ} \mathrm{C}$ & 6.30 & ASTM D445-06 \\
Pour point, ${ }^{\circ} \mathrm{C}$ & 11 & ASTM D97 \\
${ }^{\circ}$ API & 42.4 & AccuPyc II 1340 pycnometer \\
WAT, ${ }^{\circ} \mathrm{C}$ & 28 & ASTM D2500 \\
Density, g/cm & 0.814 & AccuPyc II 1340 pycnometer \\
Wax content at $20{ }^{\circ} \mathrm{C}$ & 8.9 & Modified UOP 46-64 \\
\hline
\end{tabular}

DV-III viscometer, Differential Scan Calorimeter (DSC) and AccuPyc II 1340 Pycnometer, respectively.

\section{Experimental}

The preparation of PPDs copolymer has been conducted in a three-neck flask of $250-\mathrm{mL}$ with a nitrogen gas inlet, a thermometer, a magnetic stirrer and a reflux condenser. The free-radical solution polymerization technique has been utilized to synthesize a copolymer of (SA-co-BA). Five various mass ratios that impact the synthesis of the copolymer $(1: 1,1: 2,1: 3,2: 1$ and 3:1) under fixed condition $90{ }^{\circ} \mathrm{C}$ of temperature, $7 \mathrm{~h}$ of time, and concentration of initiator of $1 \% \mathrm{wt}$ of a total of monomers.

In the first step, the amount of monomers was dissolved in a toluene solution and added to the neck flask with fixed stirring using a nitrogen atmosphere $\mathrm{N}_{2}$ for $1 \mathrm{~h}$. In the second step, during the first hour of the preparation, benzoyl peroxide (BPO) was dissolved in toluene solution and then injected into the neck flask every $15 \mathrm{~min}$ drop by drop to avoid losing the temperature of the reaction. Once the reaction is completed, the copolymer solution was kept at $27^{\circ} \mathrm{C}$. Subsequently, the third step was precipitation, and the copolymer solution was transferred to a glass beaker, and the solution of methanol was added drop by drop to the mixture of the copolymer. It was noted that once the solution of methanol had been dropped into the solution of a copolymer, the copolymer began to be to produced and grew along with a fast speed of stirring. Thereafter, the product was washed three times by methanol and filtered to avoid any impurities into the copolymer. Lastly, the copolymer was dried overnight in the vacuum oven at $60{ }^{\circ} \mathrm{C}$ (Elarbe et al. 2019). The chemical reaction is shown in (Scheme 1).

\section{Characterization of polymeric additives}

\section{Gel permeation chromatography (GPC)}

The weight-average molecular weight $\left(\mathrm{M}_{\mathrm{w}}\right)$ and numberaverage molecular weight $\left(\mathrm{M}_{\mathrm{n}}\right)$ of the synthesized (SA-coBA) copolymer PPDs at various mass ratios were performed using GPC equipped with column $2 \times$ PLgel $5 \mu \mathrm{m}$ Mixed-C, $7.5 \times 300 \mathrm{~mm}$ and refractive index detector. The samples were diluted in tetrahydrofuran THF at room temperature which was used mobile phase, and $50 \mu \mathrm{l}$ of volume was injected into the column at $0.6 \mathrm{~mL} \mathrm{~min}^{-1}$ of flow rate. The calibration standard substance used was polystyrene at concentration of $1 \mathrm{~g} / \mathrm{L}$. Polydispersity is calculated as $\mathrm{Mw} / \mathrm{Mn}$, and the results are shown in Table 2.

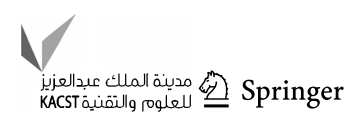


Scheme 1 Structure of stearyl acrylate-co-behenyl acrylate copolymer

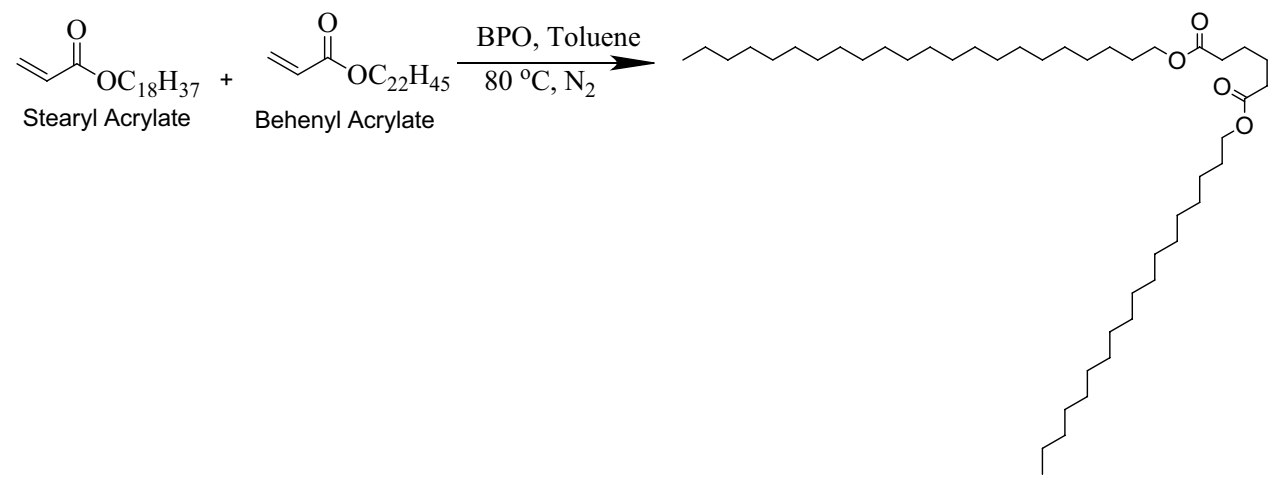

Table 2 Molecular weight of copolymers

\begin{tabular}{llll}
\hline Mass ratios wt.\% & $\mathrm{M}_{\mathrm{W}}(\mathrm{g} / \mathrm{mol})$ & $\mathrm{M}_{\mathrm{n}}(\mathrm{g} / \mathrm{mol})$ & PDI \\
\hline $1: 1$ & 23,570 & 3244 & 7.26 \\
$2: 1$ & 24,593 & 5682 & 4.32 \\
$3: 1$ & 24,715 & 3911 & 6.31 \\
$1: 2$ & 20,831 & 3730 & 5.58 \\
$1: 3$ & 19,077 & 3651 & 5.22 \\
\hline
\end{tabular}

*PDI is polydispersity index, $\mathrm{M}_{\mathrm{w}}$ is weight-average molecular weight, and $\mathrm{M}_{\mathrm{n}}$ is number-average molecular weight

\section{FTIR analysis}

The FTIR spectrum of synthesized PPD was used to identify functional groups (Perkin Elmer Spectrum 100 United State). Transmittance (\%) measurement was conducted from 400 to $4000 \mathrm{~cm}^{-1}$ wavelength range for 32 scans at a resolution of $2 \mathrm{~cm}^{-1}$.

\section{${ }^{1} H$ NMR analysis}

${ }^{1} \mathrm{H}$ NMR is one of the most useful instrumental techniques for characterizing polymeric materials used to determine and draw the chemical structure and purity of the sample. ${ }^{1} \mathrm{H}$ NMR spectra of SA-co-BA copolymer was recorded using Bruker Ultra Shield Plus NMR spectrometer at $500 \mathrm{MHz}$. ${ }^{1} \mathrm{H}-\mathrm{NMR}$ spectra using $5 \mathrm{mg}$ of sample was typically enough to obtain NMR spectra with an excellent signal. The copolymer samples were diluted in deuterated chloroform $\left(\mathrm{CdCl}_{3}\right)$ as a solvent at room temperature with tetramethylsilane TMS as an internal standard.

\section{SEM analysis}

The microstructure of SA-co-BA copolymers has been examined. The copolymers samples were conducted using an FEI Quanta 450 scanning electron microscope processed at an accelerating voltage of $15 \mathrm{kV}$. SEM was used to image the morphology of SABA copolymer particles. The SEM samples were placed on double-sided stainless-steel stubs with a drop of diluted dispersion, dried, and then JFC-1100E sputtered with 10-20-nm-thick layer of gold.

\section{XRD analysis}

The samples of poly (stearyl acrylate-co-behenyl acrylate) copolymer were performed using the Bruker $\mathrm{d} 8$ advance model $(40 \mathrm{kV}, 40 \mathrm{~mA})$ with $\mathrm{Cu} \mathrm{K} \alpha$, Nifiltered radiation $(\lambda=1.5406 \AA)$ and fitted with a computer software program. The XRD was used for phase identification of crystalline material for powder and thin film and to determine the crystal structure of unknown material. The SA-co-BA copolymer sample was put in the sample holder and scanned at a rate of $2 \%$ min at $2 \theta$ from 10 to $100^{\circ}$. Due to the amorphous and crystalline form in the diffraction process, the crystallinity was determined by separating the intensities. Then the computer-aided curve resolution method was utilized to disperse crystalline and amorphous diffractogram phases.

\section{Pour point measurement}

The (SA-co-BA) copolymers at various mass ratios (1:1, 1:2, 2:1, 1:3 and 3:1) have been synthesized, and each mass ratio has been prepared with three different concentrations from 500 to $5000 \mathrm{ppm}$. The concentrations have been injected into the blank fluid at $60{ }^{\circ} \mathrm{C}$ to ensure full dissolution of the paraffin wax component with a constant stirring of solution for homogenization. The test jar was then filled with a fluid sample and placed into the cooling bath of Koehler's Cloud point to allow the growth of wax crystals. Thereafter, the test jar was carefully removed and slanted horizontally at around $9{ }^{\circ} \mathrm{C}$ above the predicted pour point and for each additional $3{ }^{\circ} \mathrm{C}$. This process was continued in the same way until a point was reached at which the fluid in the test jar was completely cooled, and the jar was holding horizontally for $5 \mathrm{~s}$. If the fluid did not move, then the temperature was recorded, and $3{ }^{\circ} \mathrm{C}$ was added to the corresponding temperature and has recorded 
as temperature of the pour point. Table 2 shows in detail the effect of (SA-co-BA) copolymers on the pour point of the fluid.

The results were defined as a decrease in the pour point of a blank fluid, which was determined using the equation below (1):

Reduction of pour point $(\Delta \mathrm{PP})=\mathrm{PP}_{\text {untreated }}-\mathrm{PP}_{\text {treated }}$

where PP treated and untreated are the pour point of the fluid with and without the addition of SA-co-BA PPD inhibitor, respectively. The depressing in the pour point of waxy fluid is represented by $\Delta \mathrm{PP}$.

\section{Rheological measurement}

The study of flow modeling involves knowledge of crude oil's rheological behavior, and crude oil's complex behavior is investigated. It is also essential to comprehend the relationship between shear rate and shear stress. It is critical to know the impact of different factors on rheological behavior in order to design flow variables that ensure the crude oil transport through pipelines. The pressure drop through a channel is often explicitly correlated with the fluid's viscosity. Several rheological studies have been carried out to determine the flow activity of this crude oil. Despite the existence of several experimental models for crude oil flow through pipelines, none of them can reliably predict their behavior (Kumar et al. 2018). Crude oil viscosity is one of the rheological measurements that affect crude oil properties, especially during the cold flow. Therefore, three factors affect the viscosity, which are temperature, shear rate and shear stress. The Brookfield DV-III viscometer was connected with spindle form (31) viscometer which was used to measure crude oil samples' apparent dynamic viscosity. The approach used was compatible with the ASTM D44506 standard. Prior to the viscosity test, the fluid sample was prheated to a constant temperature above WAT in order to remove all wax crystals. After that, approximately $8 \mathrm{~mL}$ of fluid sample was placed into cylinder of stainless-steel with a jacket and a thermostat-controlled circulating water bath.

The dynamic viscosity of crude oil has been calculated at the different shear rate from 34 to $68 \mathrm{~s}^{-1}$ and temperatures from above and lower than WAT $\left(5-30^{\circ} \mathrm{C}\right)$. Also, the degree of viscosity reduction (DVR) has been determined using Eq. (2).

$\mathrm{DVR} \%=\frac{\mu \text { untreated }-\mu \text { treat }}{\mu \text { untreated }} * 100$

where $\mu_{\text {treated }}$ and $\mu$ untreated is the fluid viscosity with and without the addition of wax inhibitor SA-co-BA PPD, respectively.

\section{Cold finger analysis}

The apparatus of cold finger has been utilized to evaluate the wax deposition of fluid, as shown in Fig. 1. This device is appropriate for understanding the relationship between the temperature of bulk fluid and the wall that is exposed to the temperature lower WAT. To start the experimental run, $300 \mathrm{~mL}$ of waxy fluid samples were heated above WAT for thermal treatment for $1 \mathrm{~h}$ to dissolve any precipitated wax before being filled into the vessel of stainlesssteel. The experiments were performed for $2 \mathrm{~h}$, and it was important to maintain the temperature of the fluid sample at $50{ }^{\circ} \mathrm{C}$, stirring rate of the impeller of $200 \mathrm{rpm}$, and temperature of a cold finger of $5{ }^{\circ} \mathrm{C} .10 \mathrm{~mL}$ of the total amount of inhibitor was injected into the vessel at three different concentration $(1000,3000,5000 \mathrm{ppm})$ for every run. The experimental runs have been replicated three times to find accurate data. Then, the amount of deposit was scraped off from surface tube of the cold finger and then weighed to estimate the paraffin inhibition efficiency (PIE), as revealed in Eq. (3). The value of parameters is selected based on the available literature (Ridzuan et al. 2016; Ridzuan and Al-Mahfadi 2017; Ridzuan et al. 2020a, b; Ridzuan et al. 2020a, b).

$\mathrm{PIE}(\%)=\frac{\mathrm{Wf}-\mathrm{Wt}}{\mathrm{Wf}} \times 100$

where $w_{f}$ and $w_{t}$ is the reference amount of wax deposition of untreated crude oil and treated crude oil by SA-co-BA copolymer inhibitor, respectively.

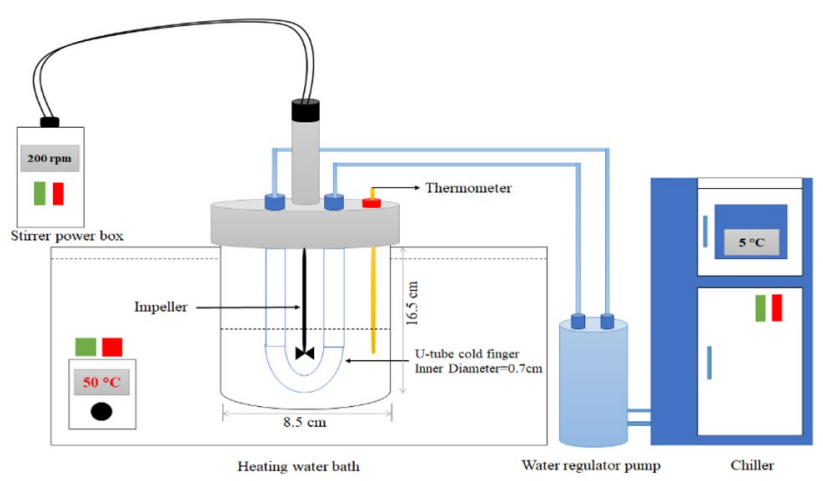

Fig. 1 Cold finger apparatus

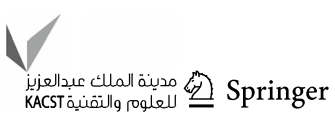




\section{Results and discussion}

\section{Characterization of SA-co-BA copolymer}

\section{Determination of molecular weight}

In general, it was thought that PPDs with weight-average molecular weights ranging from 4000 to $100,000 \mathrm{~g} / \mathrm{mol}$ had a good effect on lowering PP. The data show that the synthesized PPDs have an average molecular weight ranging from $2.47 \times 10^{4}$ to $1.9 \times 10^{4}$, which is within the chosen molecular weight range, with small discernible differences between them. Furthermore, the value of polydispersity index was ranged from 7.26 to 4.32 , which was appropriate for the study, despite the fact that the polydispersity index of the five copolymers differed slightly, particularly at (1:1) mass ratio. As a result, they can be applied as crude oil PPDs. On the other hand, the value of polydispersity which is lower than 1 , indicates that the distributions of molecular weight are very narrow, and the PPDs are predictable to become more linear which also reflect their highest thermal stability. In contrast, it is believed that the distributions of molecular weight are very wide when the polydispersity wax more than 2, and the PPDs become more branching compared to others ( $\mathrm{Du}$ et al. 2012; Ghosh et al. 2017). Table 2 shows a summary of the findings. The molecular weight results showed that increasing stearyl acrylate content at mass ratio $2: 1$ and $3: 1$ increased the weight-average molecular weight from 23,570 to $24,715 \mathrm{~g} / \mathrm{mol}$, while increasing behenyl acrylate content at mass ratio 1:2 and 1:3 decreased the weightaverage molecular weight from 23,570 to $19,077 \mathrm{~g} / \mathrm{mol}$. It was observed that mass ratio $(3: 1)$ of stearyl acrylate -co- behenyl acrylate has the highest molecular weight. It indicated the molecular weight increases as the PPD activity increases. The larger molecular weight, which lowers the pour point through co-crystallization with depressants, prevents the crystal lattice from growing (Hao et al. 2019; Sivakumar et al. 2018). In contrast, the polydispersity increased with equimolar ratios of SA and BA. Increases in the polydispersity index PDI improve wax inhibition, implying that copolymers with the highest PDI achieve the best PP depression (Hao et al. 2019).

\section{FTIR spectroscopy}

The composition of the copolymers was confirmed by IR spectroscopy. The FTIR spectra of the copolymer prepared at different mass ratios are shown in Fig. 2. The typical highest peaks at $2848.09 \mathrm{~cm}^{-1}$ and $2914.86 \mathrm{~cm}^{-1}$ were attributed to the stretching vibrations of $-\mathrm{CH} 2-$ and $\mathrm{CH} 3-$,

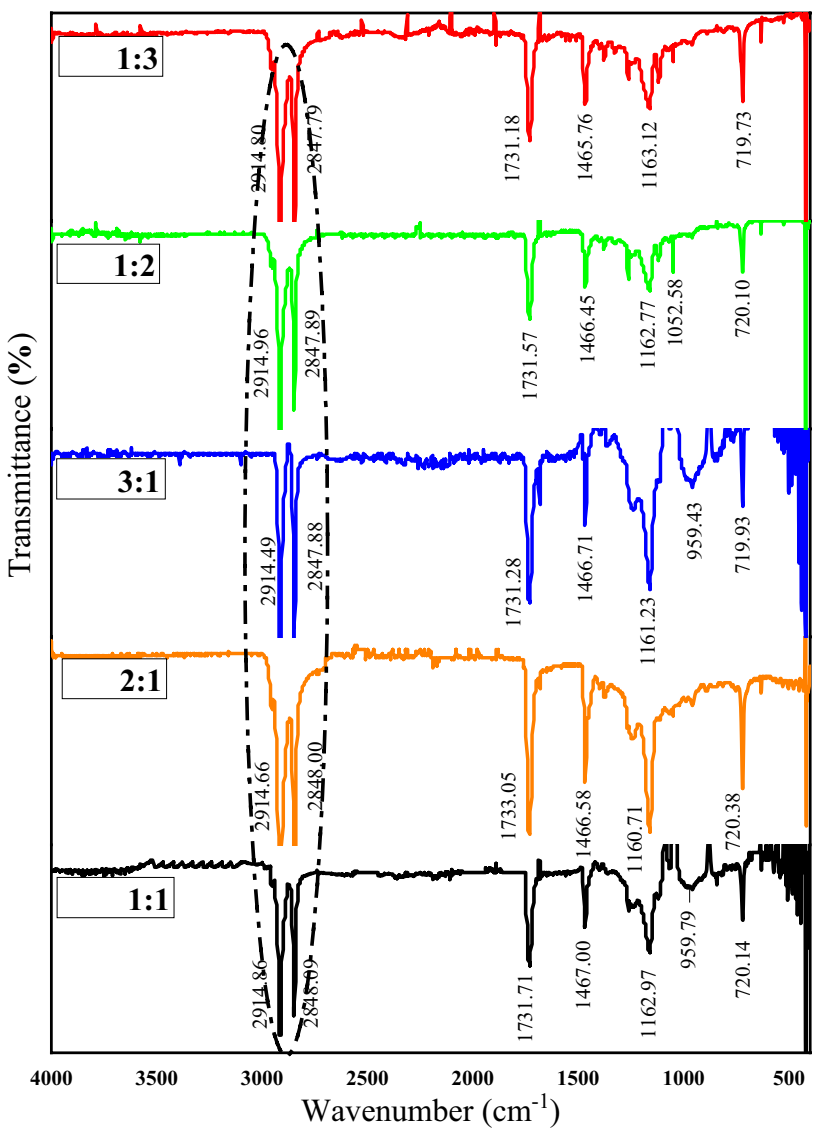

Fig. 2 FTIR spectra of poly (SA-co-BA) at a various mass ratio

respectively, because of asymmetrical $\mathrm{C}-\mathrm{H}$ stretching vibrations; the characteristic $\mathrm{C}=\mathrm{O}$ sharp absorption peaks at $1731.71 \mathrm{~cm}^{-1}$ of ester group is related to stretching of the carbonyl group $(\mathrm{C}=\mathrm{O})$; the peak appeared at 1468 of bending vibration is belong to stretching of $\mathrm{C}-\mathrm{H}$ bonds; the $-\mathrm{C}-\mathrm{O}-\mathrm{C}-$ stretching vibration peaks of epoxy group were at $1162.77 \mathrm{~cm}^{-1}$ and $1163.12 \mathrm{~cm}^{-1}$, respectively. Furthermore, the absorption peak at $720.14 \mathrm{~cm}^{-1}$ has exhibited for the long alkyl chain $\left(-\left(\mathrm{CH}_{2}\right)_{\mathrm{n}}\right.$ where $\left.n>4\right)$. These findings were barely discernible from the ones found via Xie et al. (2019) (Xie et al. 2019). These peaks showed functional groups in poly of SA-co-BA synthesized such as carbonyl, carboxylic, aldehyde and epoxy. Moreover, it was noted that no peaks in poly of SA-co-BA were found around $3200-3600 \mathrm{~cm}^{-1}$ which suggest the copolymer did not include function groups of alcoholic acid hydroxyl $(-\mathrm{COOH})$ and hydroxyl $(-\mathrm{OH})$, respectively.

Also, the vibration band of the SA monomer and BA monomer is belonging to vinyl group $\mathrm{C}=\mathrm{C}$ at $1632 \mathrm{~cm}^{-1}$ were absent after the polymerization. Furthermore, the disappearance of absorption peaks at $1632.55 \mathrm{~cm}^{-1}$ and $1635.24 \mathrm{~cm}^{-1}$ of the vinyl group $(\mathrm{C}=\mathrm{C})$ has been noted at all mass ratios. These findings have a good similarity with 
other investigators (Darvishi et al. 2013; Elarbe et al. 2021; Handayani et al. 2019; Xie et al. 2019; Zhang et al. 2020). Consequently, it may be concluded that the copolymer of SA-co-BA PPD has been successfully synthesized at different mass ratios.

\section{${ }^{1} \mathrm{H} N M R$ spectroscopic}

The long chains of SA and BA monomers are considered to play a significant role in the kinetic actions of radical operations. ${ }^{1} \mathrm{H}$ NMR spectral analysis has characterized the chemical structure and composition of the (SA-coBA) copolymer. As revealed in Fig. 3a and b, the chemical shifts of methylene and methyl groups in SA and BA monomers occur at $0.88,1.26,1.62$ and $3.97 \mathrm{ppm}$, which related to $-\mathrm{CH} 3,-\mathrm{CH} 2-,-\mathrm{CH}-$ and $-\mathrm{C}=\mathrm{O}-\mathrm{CH} 2-$ protons, respectively. Meanwhile, 5.59, 6.05 and $6.27 \mathrm{ppm}$ belong to double bond peaks $-\mathrm{C}=\mathrm{C}-$ protons, and all recorded peaks are shown in the structure. On the other hand, the chemical structure of five different mass ratios synthesized copolymer is shown in Fig. 3c. The ethylene group's chemical shift was transformed from 3.97 to $4.15 \mathrm{ppm}$. These results
Fig. $3{ }^{1}$ HNMR spectra of (a) SA monomer and (b) BA monomer (c). ${ }^{1} \mathrm{H}$ NMR spectra of poly SA-co-BA at a various mass ratio
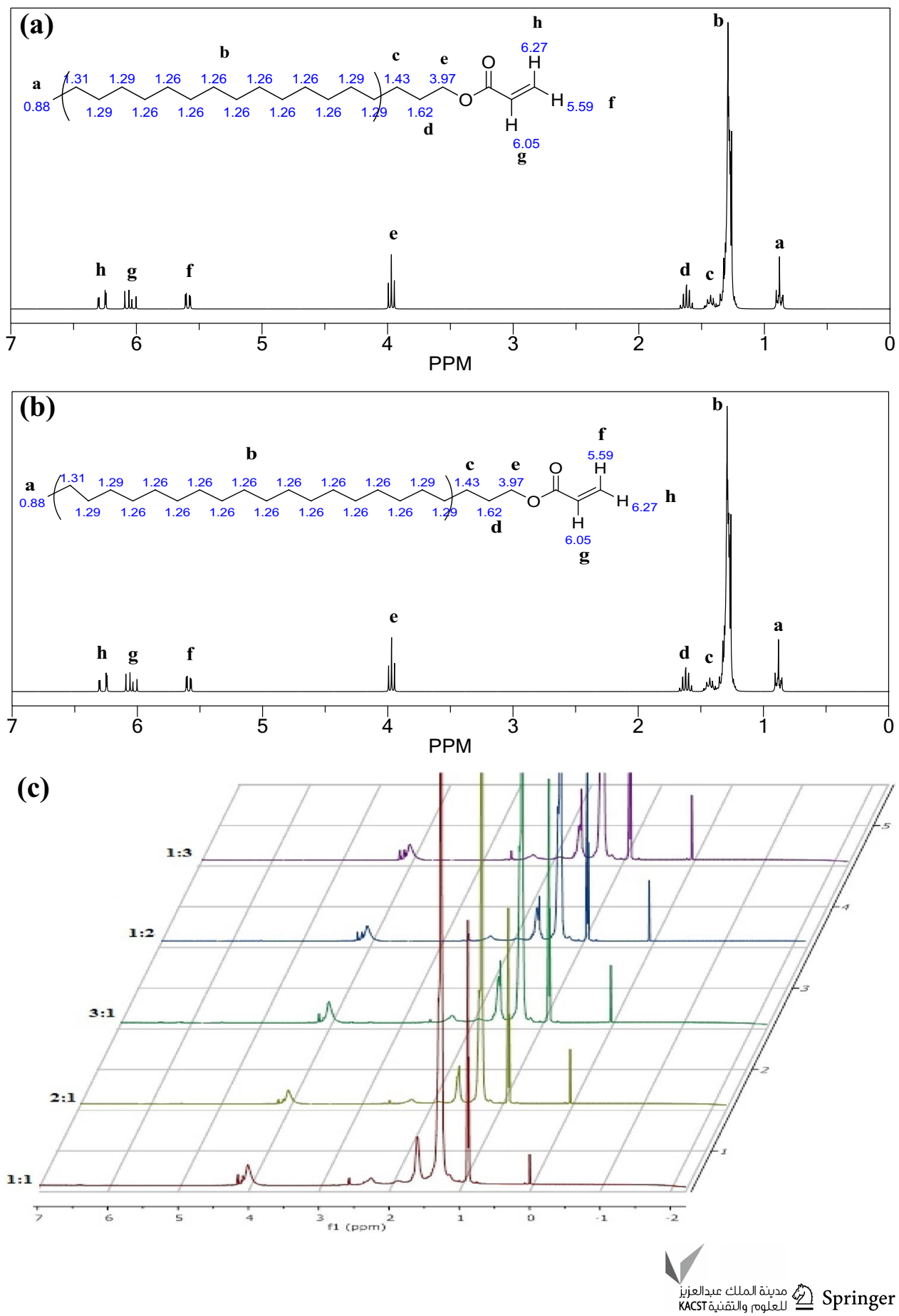
were similar to the conclusions stated by the observation of Handayani et al. (2019) (Doguscu and Alkan 2015; Handayani et al. 2019).

Also, after polymerization, the double bond peaks $(\mathrm{C}=\mathrm{C})$ located between 5.59, 6.05 and $6.27 \mathrm{ppm}$ have disappeared as expected. Copolymer spectra without the $=\mathrm{CH} 2$ resonance peaks are 5.5-6.5 ppm, and similar behavior of findings was obtained by Xie et al. (2019) and Zhang et al. (2020) (Xie et al. 2019; Zhang et al. 2020). This indicated that SA and BA had been polymerized, and the double bond was transformed into a single bond $(\mathrm{C}-\mathrm{C})$. This proves that as a result of polymerization, most of the vinyl monomers contributed to polymers. Also, the number of $\mathrm{H}$ protons and chemical shifts have been in good agreement with SA (Huda et al. 2017; Soliman et al. 2018; Zhu et al. 2018). Furthermore, the synthesis of the copolymer at different mass ratios was successful and confirmed by the appearance of the signal at $2.4 \mathrm{ppm}$, which is attributed to the $\mathrm{CH}$ protons of amide functionality and the disappearance of the vinyl proton signal at 5.59-6.27 ppm, as shown in Fig. 3c. All experiments indicated that the copolymer samples were successfully synthesized at different mass ratios.

\section{X-ray diffraction XRD}

The primary purpose of $\mathrm{x}$-ray diffraction analysis is to identify peaks and crystallization of (SA-co-BA) copolymer. The X-ray diffraction pattern of poly (SA-co- BA) has been shown in Fig. 4. A sharp diffraction peak appeared at $2 \theta=21.5^{\circ}$, which corresponds to $4.14 \AA$ spacing that is harmonic with the typical diffraction peak of the copolymer in the crystalline form, and similar results were obtained by Goswami et al. (2019), Huda et al. (2017) and Rodbari et al. (2016). This value corresponds to the van der Walls contract of non-bonded atoms in several long-chain acrylates and methacrylates comb-like polymers. (Sarmah and Baruah 2003). The SA monomer displays a diffraction peak at $2 \theta=21.2^{\circ}$, which is equal to a spacing of $0.42 \mathrm{~nm}$ in the crystal lattice. The poly of SA-co-BA with different mass ratios displays a diffraction peak almost around $2 \theta=21.5^{\circ}$, corresponding to a spacing of $0.41 \mathrm{~nm}$ in the crystal lattice. This diffraction is due to the crystalline state of the long alkyl chain formed by SA. The spacing of the crystal lattice of the copolymer is $0.01 \mathrm{~nm}$ smaller than the one of the SA monomer, suggesting the addition of the short side chain monomer BA to increase the crystal density of the copolymer. A small peak exhibited at $23.5^{\circ}$ (d $3.75 \AA$ ). This peak could be attributed to orthorhombic packing. Based on a thorough examination of conventional comb-like polymers (Sarmah and Baruah 2003).

\section{SEM analysis}

Figure 5 describes the morphology of copolymer synthesized with various mass ratios of poly SA-co-BA. In all ratios, the SA-co-BA copolymer surface displays many folds that are irregularly stacked together. Many points below the fold indicate that the SA-co-BA copolymer onto SA surfaces was homogeneous. The images also show the presence of rugged surfaces. This is primarily because of the strict adherence between the SA and the SABA copolymer. The addition of the SA monomer resulted in the hollowing of the SA-co-BA morphology. Rodbari et al. (2016) and Huda et al. (2017) reported that stearyl acrylate has a sponge-like structure that permits the adding of SA to create a cavity found on the PPD copolymer. The existence of a hollow

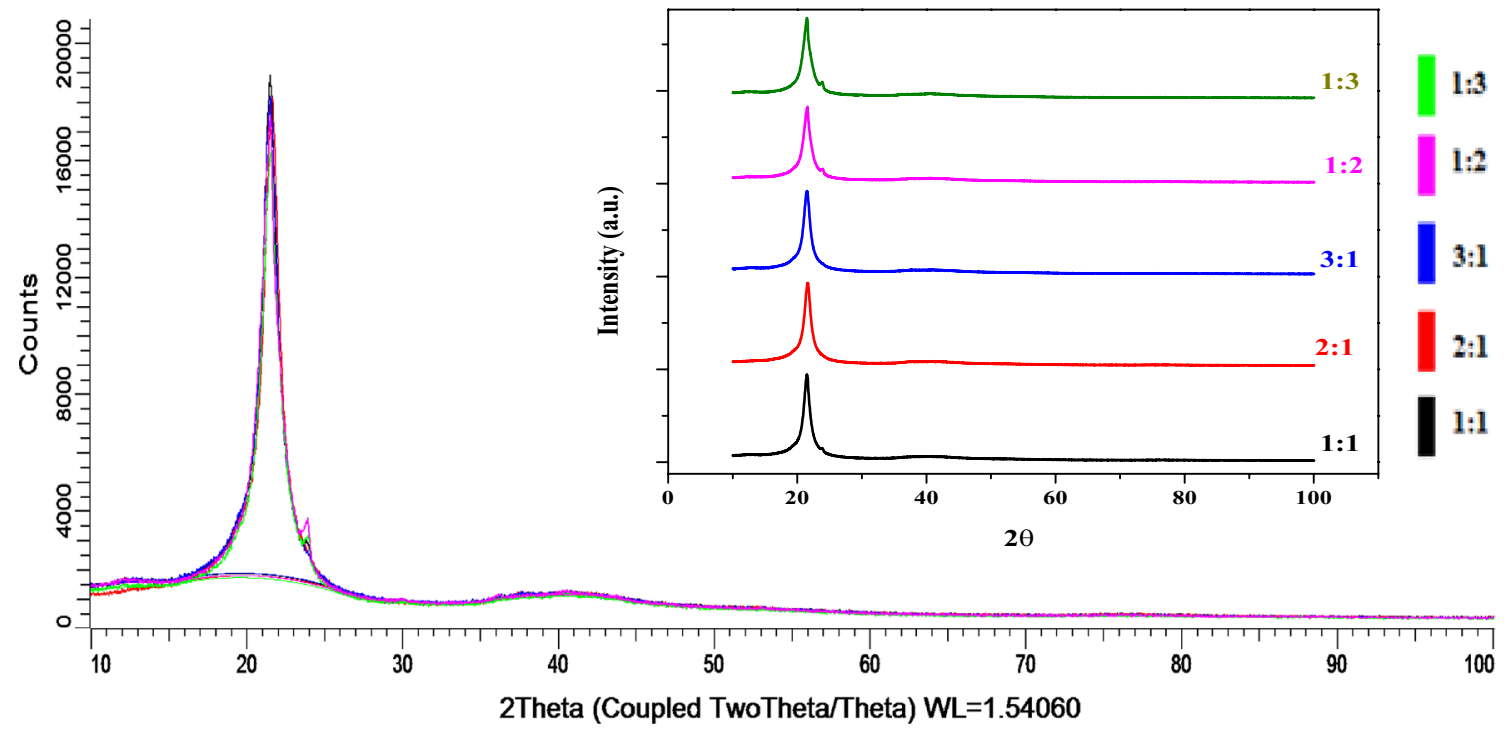

Fig. 4 X-ray diffractograms of poly SA-co-BA at a different mass ratio

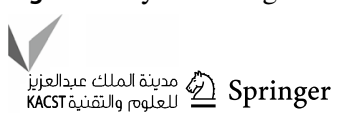



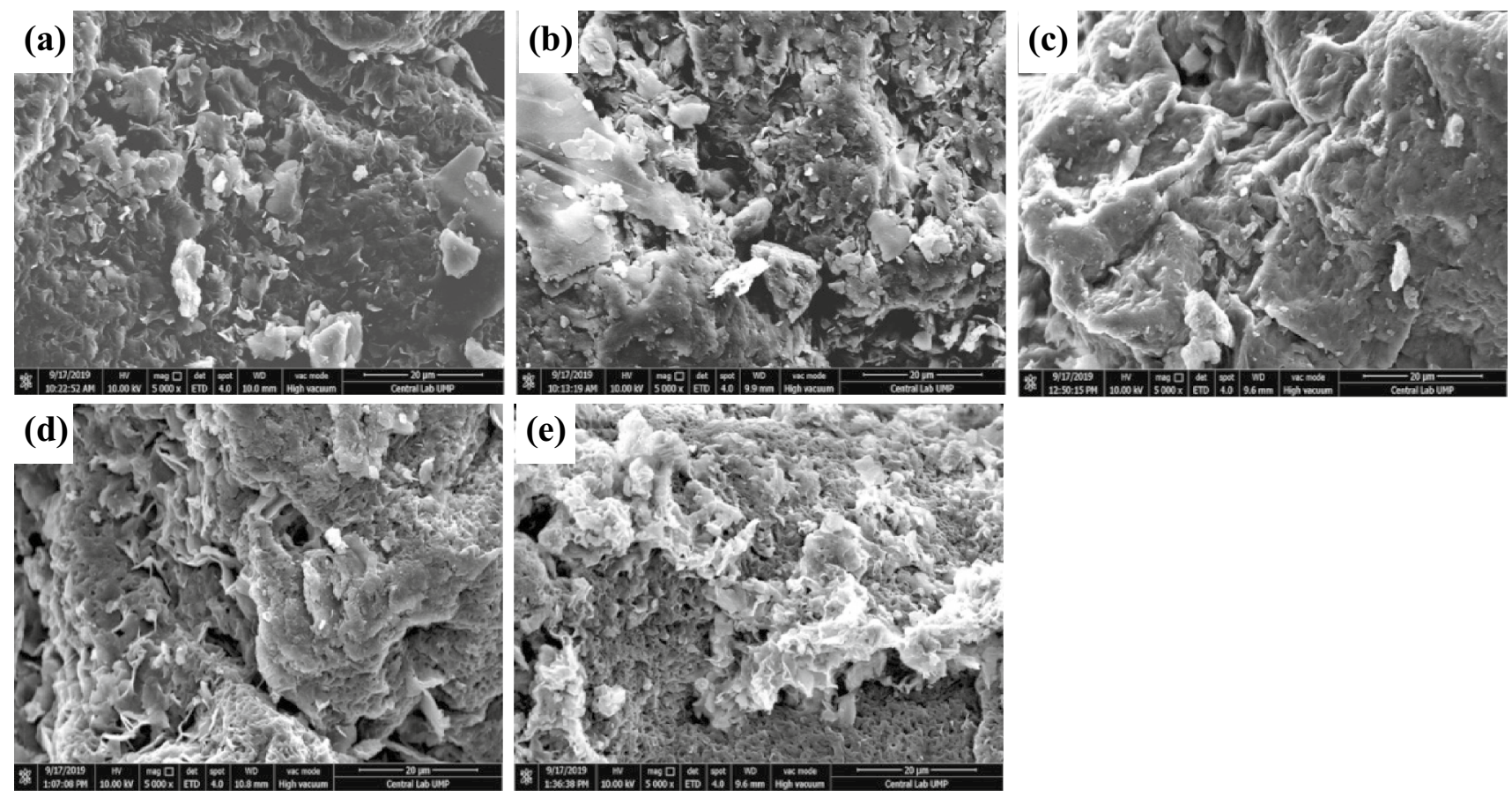

Fig. 5 SEM micrographs of poly SA-co-BA at different mass ratio (a) $1: 1$, (b) 2:1, (c) $3: 1$, (d) (1:2) and (e) $1: 3$

in the copolymer could provide some space for absorption. This conformation substantiates previous findings in the literature (Goswami et al. 2019; Rodbari et al. 2016; Zhao et al. 2018). Further evidence of surface morphology should be confirmed using FESEM.

\section{Evaluation of SABA copolymer on pour point}

The Pour Point is the lowest temperature at which a fluid becomes semisolid and loses its flowing properties under standard cooling conditions (Akhil et al. 2017). Pour point (PP) of the blank crude oil was found to be $11^{\circ} \mathrm{C}$. Table 3 shows the decrease in pour point of different concentrations (500-5000 ppm) of each mass ratio of copolymer as additives to treated crude oil. It was noted that the values of pour point have been efficiently reduced as the concentration of
SABA increased up to 5,000 ppm. This implies that at these concentrations, the SABA copolymer will co-crystallize with paraffin and change its crystals. Overall, the sideway growth of the crystal faces can be slightly limited at lower concentrations of additive. Consequently, crystallization can still be capable of formation. However, sideway growth becomes more difficult for the wax crystals at higher concentrations of the additives. The prepared copolymers were studied for waxy crude oil as PPDs and flow improvers.

The first mass ratio $(1: 1)$ depression the pour point of the waxy fluid from $11{ }^{\circ} \mathrm{C}$ to $2{ }^{\circ} \mathrm{C}, 3{ }^{\circ} \mathrm{C}$ and $2{ }^{\circ} \mathrm{C}$ at $1000 \mathrm{ppm}, 3000 \mathrm{ppm}$ and $5000 \mathrm{ppm}$ of concentrations, respectively, as shown in Table 3 . The second mass ratio (2:1) at a concentration of $5000 \mathrm{ppm}$ gave a better result relative to other concentrations, where the pour point of the waxy fluid decreased from 11 to $2{ }^{\circ} \mathrm{C}$. The third
Table 3 The effect of SABA copolymer on depression of pour point

\begin{tabular}{llllllllll}
\hline $\begin{array}{l}\text { Mass } \\
\text { ratio, } \\
\text { wt\% }\end{array}$ & Pour Point $\left({ }^{\circ} \mathrm{C}\right)$ & \multicolumn{7}{c}{$\begin{array}{l}\text { Concentra- } \\
\text { tions of } \\
\mathrm{PPD}\end{array}$} \\
& Blank & $500 \mathrm{ppm}$ & $\Delta \mathrm{PP}{ }^{\circ} \mathrm{C}$ & 1000 & $\Delta \mathrm{PP}{ }^{\circ} \mathrm{C}$ & 3000 & $\Delta \mathrm{PP}{ }^{\circ} \mathrm{C}$ & 5000 & $\Delta \mathrm{PP}^{\circ} \mathrm{C}$ \\
\hline $1: 1$ & 11 & 5 & 6 & 2 & 9 & 3 & 8 & 2 & 9 \\
$2: 1$ & 11 & 7 & 4 & 3 & 8 & 4 & 7 & 2 & 9 \\
$3: 1$ & 11 & 6 & 5 & 4 & 7 & 3 & 8 & 4 & 7 \\
$1: 2$ & 11 & 6 & 5 & 4 & 7 & 5 & 6 & 3 & 8 \\
$1: 3$ & 11 & 7 & 4 & 4 & 7 & 5 & 6 & 3 & 8 \\
\hline
\end{tabular}

$* \Delta \mathrm{PP}$ represents a reduction in the pour point of the crude oil 
mass ratio (3:1) at $3000 \mathrm{ppm}$ concentration can reduce the pour point of the crude oil from 11 to $3{ }^{\circ} \mathrm{C}$. The fourth and last mass ratio (1:2) and (1:3) at $5000 \mathrm{ppm}$ of concentration can reduce the pour point of the oil from 11 to $3{ }^{\circ} \mathrm{C}$, respectively. This implies that at these concentrations range, the SABA additive may co-crystallize with the crude oil and changes their crystals. Optimum mass ratio of SABA copolymer was (1:1) at $1000 \mathrm{ppm}$ of concentration, where the highest depression from 11 to $2{ }^{\circ} \mathrm{C}\left(\triangle \mathrm{PP}=9{ }^{\circ} \mathrm{C}\right)$, while at the same concentration, the minimum reduction was showed by $(3: 1,1: 2$ and 1:3) of mass ratio, from 11 to $4{ }^{\circ} \mathrm{C}\left(\triangle \mathrm{PP}=7^{\circ} \mathrm{C}\right)$. The mass ratio (1:3) showed a similarity effect at $1000 \mathrm{ppm}$ where $\left(\triangle \mathrm{PP}=7{ }^{\circ} \mathrm{C}\right)$, but with increasing the concentration at $5000 \mathrm{ppm}$, the pour point increased in the positive impact and achieved depression $\left(\triangle \mathrm{PP}=8^{\circ} \mathrm{C}\right)$.

On the other hand, it was discovered that when the inhibitor concentration is raised from 500 to $1000 \mathrm{ppm}$, the depression of the pour point rises, and there is a slight rise in the pour point of crude oil beyond the optimum concentration of SABA PPD, due to the addition of an extra concentration of SABA copolymer, which becomes suspended and induces gelling in the fluid, thus the flow of crude oil becomes slower, and wax begins to form linkages. Furthermore, the copolymer becomes bulkier as the PPD concentration rises, making it less soluble and ineffective, and thereby raising the pour point. (Al-Sabagh et al. 2016; Deka et al. 2018). In particular, sideways crystal face growth can be reduced at lower PPD concentrations, resulting in a slower crystal growth rate, though crystallization may still be possible. The side way growth of wax crystals becomes even more complicated at higher additive concentrations (Al-Sabagh et al. 2009). In addition, the presence of nonpolar groups (octadecyl and behenyl) bonded on the surface of the amide alters the composition of precipitated wax crystals and improves their dispersion in crude oil. Consequently, all mass ratios of SABA copolymer have ability to disperse wax crystals in oil phase. The SABA copolymer can change the size and shape of wax crystals while also inhibiting their aggregation. It also exhibited a synergistic impact by improving the matching of PPDs and wax crystals.(Xu et al. 2018).

The mass ratio (1:1) exhibited a positive influence on depression of the pour point, and the $\triangle \mathrm{PP}$ was $9^{\circ} \mathrm{C}$ against 1000 and $5000 \mathrm{ppm}$, respectively. This means that the mass ratio of (1:1) was a better match with wax chains and prevented the formation and growth of wax crystals. Therefore, the longer chain (1:1) of mass ratio has improved with the presence of the wax paraffin chains in the fluid and acted to prevent their easy crystallization. The depression in pour point caused by SABA copolymer may be attributed to SABA copolymer co-crystallizing with wax molecules, which changes the wax crystal morphology.
This is due to the fact that the n-alkyl chain lengths of SABA copolymer have a substantial impact on the reduction degree of PP in crude oil for all mass ratios PPDs. Since the lengths of the n-alkyl chains in PPDs are closely linked to the content of the corresponding n-alkane in hydrocarbons of crude oil, they have a significant impact on the PP. Furthermore, the PPDs' crystallization temperature range has a significant impact on their efficiency. When PPDs' crystallization temperature range matches that of the paraffin waxes, the co-crystallization effect is very high, and the PPDs have a good effect. This justifies the inference stated by Xu et al. (2018). Previously, Khidr et al, (2015) (Khidr et al. 2015) mentioned that PPD molecules adsorb on various crystal faces, resulting in normal wax crystal growth and less overlapping between wax nuclei.

\section{Rheological measurements}

Rheological measurements conducted at various temperatures demonstrated the viscosity difference. The sample of crude oil altered from Newtonian to non-Newtonian shear thinning behavior with a decrease of temperature lesser than the temperature of WAT. Furthermore, it was noted that the reduction of viscosity due to the rise of temperature led to wax crystals dissolving in the crude oil. It was noted from Fig. 6 that the difference of viscosity values with shear rates indicates that rising the shear rate leads to decrease in the viscosity (Deka et al. 2020). When temperature of crude oil falls below the pour point, the viscosity rises significantly. This point is called the abnormal point, which is the breakoff point of non-Newtonian and Newtonian shear thinning behavior. The PPDs can decrease the viscosity at low temperature in the range of non-Newtonian behavior. Therefore, the addition of PPDs results in viscosity reduction at an abnormal point (Feng et al. 2014).

\section{Effect of temperature on viscosity of blank crude oil}

The graph of the viscosity of blank crude oil against the temperature is shown in Fig. 6a. The rise in temperature in turn decreases viscosity, which stipulates changes in the rheological characteristics of crude oil. (Kumar et al. 2018). As described in Table 1, the temperature of pour point and WAT of Malaysian blank crude oil were measured at 11 and $28^{\circ} \mathrm{C}$, respectively. The waxes split like plate-like crystals when the temperature of oil decreases lower the WAT, these crystals interact together to create a network of threedimensional that contributes to the trapping of the oil which allows the viscosity to increase, thus reducing the oil flow assurance and loss of the pressure in pipelines (Subramanie et al. 2020). The effect of temperatures $\left(5-30^{\circ} \mathrm{C}\right)$ and shear rates $\left(34-68 \mathrm{~s}^{-1}\right)$ on crude oil viscosity was investigated, as revealed in Fig. 6a. Note that at $10{ }^{\circ} \mathrm{C}$, the viscosity of blank 

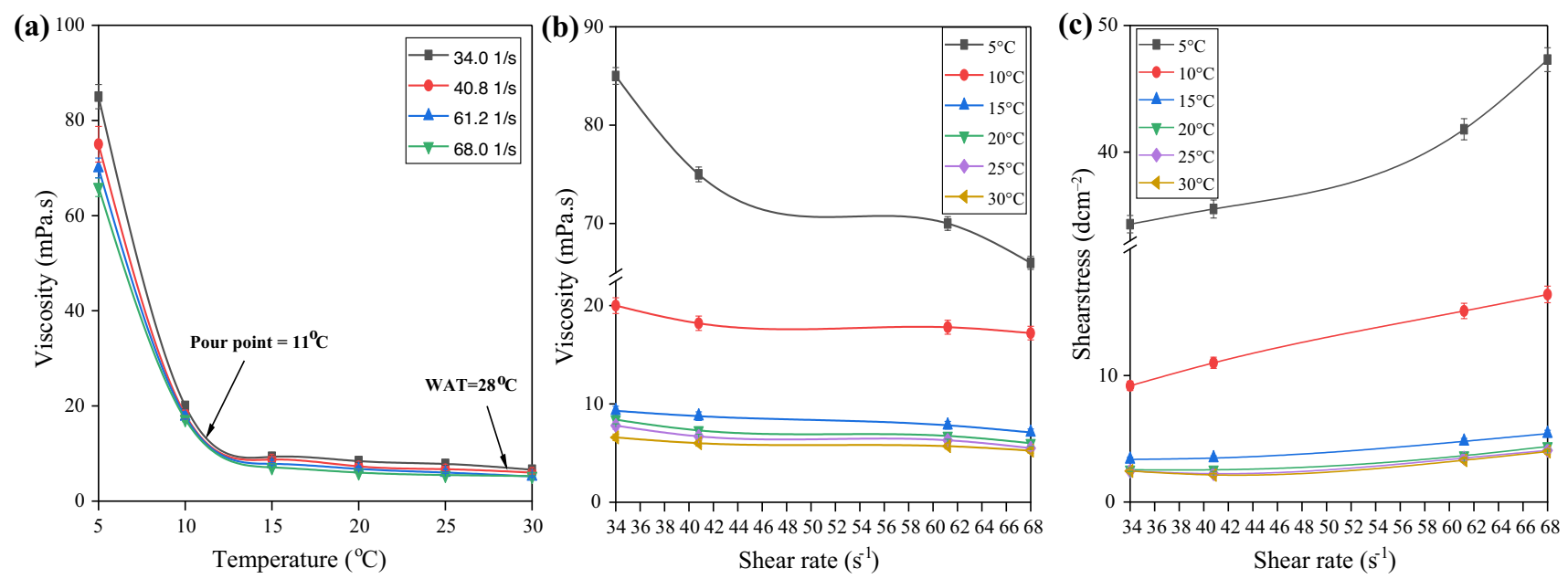

Fig. 6 (a) demonstrates the influence of temperature on the characteristic flow of Malaysian fluid behavior in terms of viscosity and shear rate. (b) The effect of shear rate on the viscosity and (c) the effect of shear rate on shear stress of blank crude oil

oil was $20,18.2,17.8$ and $17.2 \mathrm{mPa} . \mathrm{s}$ and when the temperature decreases to $5{ }^{\circ} \mathrm{C}$, the viscosity was increased significantly to $85,75,70$ and $66 \mathrm{mPa} . \mathrm{s}$ at $34.0,40.8,61.2$ and $68.0 \mathrm{~s}^{-1}$ of shear rate, respectively. In addition, results show shear rate to be one of the critical parameters which influence the viscosity. It can be concluded that viscosity rises as the temperature reductions, and the shear rate increases as the viscosity decreases, which is in strong agreement with previous work done by (Elarbe et al. 2021; Elganidi et al. 2020). The fluid viscosity at temperatures of $5^{\circ} \mathrm{C}$ and $10^{\circ} \mathrm{C}$ were higher than at higher temperatures. This is due to a rise in temperature that dissolves the wax paraffin, which remains as a liquid, consequently reducing the viscosity of crude oil. In comparison, a reduction in temperature of fluid leads to wax precipitation and increases viscosity (Kumar et al. 2018; Odutola and Idemili 2020; Taborda et al. 2016). The fluid viscosity reduces at $15,20,25$ and $30^{\circ} \mathrm{C}$ as binding energy reduces due to a decrease in the cohesive forces of the molecular compositions. The crude oil components act as solids phase at low temperatures and the viscosity depends on their breakage or alignment (Taborda et al. 2016).

The graph indicates the shear thinning of the non-Newtonian behavior over the shear rates range at which the viscosity reduces dramatically with increasing temperatures. It also displays that viscosity differences are more significant at lesser shear rates 34.0 and $40.8 \mathrm{~s}^{-1}$ than high shear rates 61.2 and $68.0 \mathrm{~s}^{-1}$. Thus, the apparent viscosity at a fixed temperature relies on value of the shear rate and reduces with rising temperature (Kumar et al. 2018; Souas et al. 2020). This can be due to the high-temperature effect on light crude oil components' viscosity and chemical structure. Also, heavy fluid viscosity depends on increases in the shear rate value, which implies the flow behavior encounters fewer resistance at maximum shear rates. The chain-like molecule of the wax crystal is dissembled and reorientated equal to the driving force as the shear rate rises, thereby decreasing the crude oil viscosity.

\section{Effect of shear rate on the viscosity and shear stress of blank crude oil}

Figure $6 \mathrm{~b}$ displays the effect of blank crude oil viscosity against the shear rate curve at changing temperatures. The graph shows that the rise in shear rates from 34.0, and $68.0 \mathrm{~s}^{-1}$ contributes to a reduction in viscosity from 85 to $66 \mathrm{mPa}$.s at $5{ }^{\circ} \mathrm{C}$. This can be due to the flow behavior encounters fewer resistance at maximum shear rates, in which long chains of wax molecules are cracked, stretched and reoriented equivalent to the driving force, dropping the crude oil viscosity (Taborda et al. 2016).

Figure $6 \mathrm{c}$ depicts the effect of shear rate on shear stress, showing that as shear rate rises, shear stress rises immediately at all temperatures, resulting in a cold flow pattern that follows the Bingham flow model. The shear rate and shear stress have a linear relationship in the untreated crude sample, particularly between WAT and the pour point. This means that Malaysian fluid held Newtonian fluid characteristics. Nevertheless, as the temperature of fluid drops below the pour point, the sample of crude oil has shown a nonNewtonian fluid behavior as the relationship of shear rate/ shear stress converted to nonlinear.

\section{Effect of wax inhibitor on viscosity of crude Oil}

Based on the best mass ratio of polymerization, which is (1:1) $\mathrm{wt} \%$, the copolymer of (SA-co-BA) has been prepared as a PPD for increasing the crude oil flowability by three different concentrations of (SA-co-BA) copolymer, which

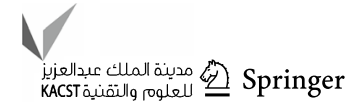


are 1000, 3000 and $5000 \mathrm{ppm}$. The analysis was conducted for the treated and blank crude oil samples to evaluate the performance of PPD concentration on viscosity at various temperatures from 5 to $30^{\circ} \mathrm{C}$, in which all samples were observed at a various shear rate from 34 to $68 \mathrm{~s}^{-1}$. Viscosity of fluid with and without the addition of SA-co-BA PPD is investigated to identify the mechanism of viscosity movement. As SA-co-BA PPD inhibitor is applied to crude oil, the copolymer molecules interacted with the molecules of fluid, weakening and preventing crude oil from forming bonds of hydrogen with carboxyl or hydroxyl groups. As a result, the viscosity of fluid is lower (Elarbe et al. 2021). The findings in Fig. 7 display that all SA-co-BA copolymer concentrations have a significant effect on lowering crude oil viscosity as compared to blank crude oil due to the high molecular weight of PPD. It was apparent that the addition of SA- $c o$-BA copolymer causes a reduction of dynamic viscosity, which is more evident at the abnormal point where the temperature of crude oil drops under the pour point.

\section{Effect of temperature on the viscosity of treated crude oil}

The viscosity of crude oil is heavier than WAT as the crude oil transitions from a liquid to an amorphous solid form. In addition, crude oil's rheological behavior is typically nonNewtonian under WAT, which supports the fact that crude oil's kinematic viscosity rises below WAT. As crude oil temperature falls, the molecules of wax started to deposit out of
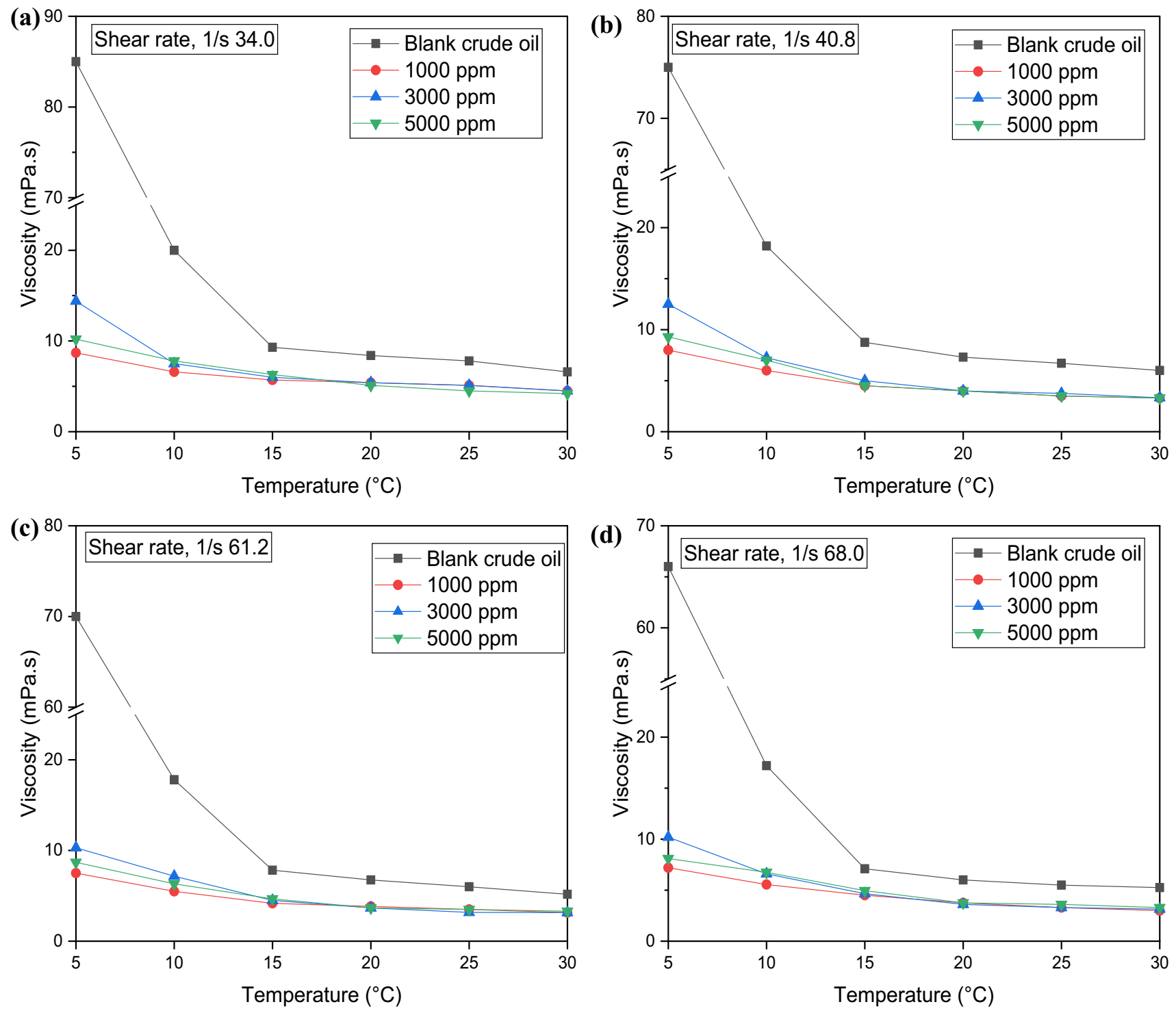

Fig. 7 Effect of temperature on the viscosity of untreated and treated fluid at different shear rate, (a) $34.0 \mathrm{~s}^{-1},(\mathbf{b}) 40.8 \mathrm{~s}^{-1}$, (c) $61.2 \mathrm{~s}^{-1}$ and (d) $68.0 \mathrm{~s}^{-1}$ 
fluid and shape a complex, three-dimensional wax structure that gradually binds the lighter components of crude oil, thereby reducing crude oil flowability (Odutola and Idemili 2020; Subramanie et al. 2020).

The effects of temperatures on viscosity at a various shear rate in terms of SA-co-BA concentrations are appeared in Fig. 7a-d. The viscosities of all treated crude oil increased slightly with the decreasing temperature from 30 to $15^{\circ} \mathrm{C}$. As the temperature decreased to below pour point, which is $11^{\circ} \mathrm{C}$, the viscosity increased dramatically. The viscosity of treated crude oil by the addition of SABA was significantly reduced compared with the blank crude oil. 1000 and $5000 \mathrm{ppm}$ of treated crude oil at all shear rates have exerted lower viscosity at a temperature lower than pour point, followed by $3000 \mathrm{ppm}$, which was the highest. At temperatures more than WAT, there was no important alteration in the viscosity with the addition of PPD. This can be clarified from the viewpoint of molecule movement. As the temperature increases, molecules of wax tend to move faster, decreasing interaction tendency. This interpretation is consistent with that of (Subramanie et al. 2020). The flowability of crude oil increases as the temperature rises, and the viscosity decreases. As a result, in offshore applications where the crude oil cools efficiently, it is important to determine the inhibitor's performance at low temperatures. The best wax inhibitor performance at cold temperatures is desirable (Odutola and Idemili 2020).

The viscosity variation was visible in rheological tests conducted at various temperatures. With a drop in temperature below the pour point, the fluid sample transitioned from Newtonian to non-Newtonian shear thinning behavior. Furthermore, the dissolving of wax crystals in fluid causes the viscosity to decrease as the temperature rises. The figures show the difference in shear rate with viscosity, which demonstrates that rising shear rate reduces viscosity. The improvement of cold flow properties can be seen in the viscosity values of 1000, 3000, and $5000 \mathrm{ppm}$ treated crude oils when compared to the blank fluid (Sharma et al. 2019).

\section{Effect of shear rate on the viscosity and shear stress of treated crude oil}

The relationship of shear rate vs viscosity of treated crude oil has been studied in Fig. 8, where viscosity decreases continuously as shear rate increases. For example, in Fig. 8a. The viscosity at $1000 \mathrm{ppm}$ and $30^{\circ} \mathrm{C}$ was $4.5 \mathrm{mPa} . \mathrm{s}$ at $34 \mathrm{~s}^{-1}$ shear rates, which begin to decrease as the shear rate rises and became $3.3 \mathrm{mPa} . \mathrm{s}$ at $40.8 \mathrm{~s}^{-1}, 3.13 \mathrm{mPa} . \mathrm{s}$ at $61.2 \mathrm{~s}^{-1}$ and $3.0 \mathrm{mPa} . \mathrm{s}$ at $68 \mathrm{~s}^{-1}$ shear rates, and then the shear rate increases almost continuously. Based on all of these results, it was exhibited that fluid exhibits characteristics of Newtonian behavior at $30^{\circ} \mathrm{C}$, which has a linear relationship, while at $5{ }^{\circ} \mathrm{C}$, the treated crude oil viscosity at the same concentration was reduced from 8.7 to $7.2 \mathrm{mPa}$.s with a rising shear rate from 34 to $68 \mathrm{~s}^{-1}$, respectively. Following that, as the shear rate at a lower rate, the apparent viscosity reduces until it reached a constant value suggesting that the steady equilibrium state has been reached. Thus, the decrease in the apparent viscosity was smaller at a maximum shear rate of $68 \mathrm{~s}^{-1}$. In this context, it was demonstrated that the tested crude oil is completely changed into non-Newtonian behavior at the pour point temperature or below based on these rheological analysis, which fit with the Bingham model wherever the fluid primarily performs as a non-Newtonian fluid (Soliman et al. 2018).

The reduction in viscosity with increasing shear rate at all test temperatures can be clarified at temperatures close the pour point, where the energy used by shear rate and dissipated power in the crude matrix begins to destroy wax crystal's structure which contributes to the reduction in
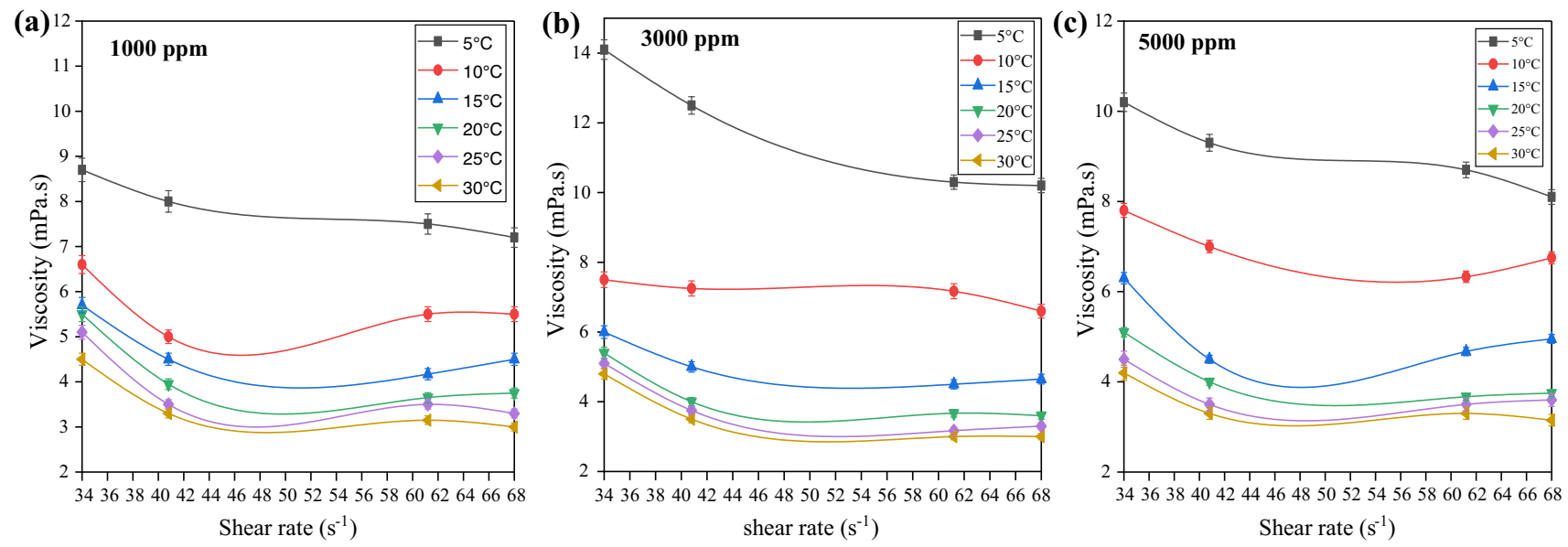

Fig. 8 Effect of shear rate on the viscosity of treated crude oil by concentrations of SA-co-BA PPD, (a) 1000 ppm, (b) 3000 ppm and (c) $5000 \mathrm{ppm}$ 
yield stress without the ability to flow. As the shear rate is increased further, the dispersed energy is insufficient to beat the yield stress and start the flow. Wax agglomerates dissipate and shrink during this level, releasing some of the continuous phases that were previously trapped within them. As a consequence, the concentration of the distributed phase decreases, which leads to a reduction in viscosity. This reduction keeps on as the shear rate is increased until the agglomerates of wax crystals are cracked down into the primary particles.

As a result, the properties of crude oil exhibit non-Newtonian behavior. The majority of the dissipated energy was aimed to minimize the progressive yield stress at lower temperatures. Thus, less effort is spent to minimize viscosity (Soliman et al. 2018).

Experimentally, it was noticed from Fig. 9a, b and c that a rise in shear rate from 34.0 to $68.0 \mathrm{~s} \mathrm{~s}^{-1}$ due to increased shear stress at all concentrations of wax inhibitor 1000, 3000 and $5000 \mathrm{ppm}$ indicated that shear rate has a directly proportional relationship with shear stress. For example, it has been shown in Fig. 9a that shear stress was $2.96 \mathrm{dcm}^{2}$ at $34.0 \mathrm{~s}^{-1}$ of shear rate and increased to $5 \mathrm{dcm}^{2}$ with increase in the shear rate to $68.0 \mathrm{~s}^{-1}$. It was also noted that it has dropped at a shear rate of $40.8 \mathrm{~s}^{-1}$ before rising at shear rates from 40.8 to $68 \mathrm{~s}^{-1}$. Shear stress allows the microstructures that connect the wax crystals to break down. As a result, the gelling rate decreases as shear stress rises, and formation wax decreases as shear stress rises. Thus, wax mitigation benefits from a higher shear rate. However, there is a small decrease in shear stress in this study at one point, which is true for all SABA inhibitor concentrations studied. The drop in shear stress because of the shear rate value may lead to a rise in crude oil viscosity. This can be explained by the fact that at a shear rate of $40.8 \mathrm{~s}^{-1}$, the wax inhibitor might not be as powerful as other shear rates. This is likely due to the shear thickening of crude oil, which allows wax crystals to grow and therefore increases the viscosity of the fluid. This interpretation is in agreement with (Subramanie et al. 2020).

It also can be observed that the shear stress is higher at a lower crude oil temperature. For instance, at $1000 \mathrm{ppm}$ and $5{ }^{\circ} \mathrm{C}$, the shear stress was $2.96 \mathrm{~d} / \mathrm{cm}^{3}$, while at $30{ }^{\circ} \mathrm{C}$ was decreased to $1.73 \mathrm{~d} / \mathrm{cm}^{3}$. This is explained by the fact that as the temperature of crude oil increases, the viscosity of the crude oil decreases, resulting in a decrease in the wax deposition force and thus a reduction in shear stress.

Figure 10 represents the effect of SA-co-BA concentrations in term of DVR. The highest DVR has been obtained at $1000 \mathrm{ppm}$ by $89.76 \%$. It has been evaluated that the best results of SA-co-BA PPD in terms of DVR of crude oil were much better in cold environments because the viscosity value of blank crude oil was high and decreased with rising

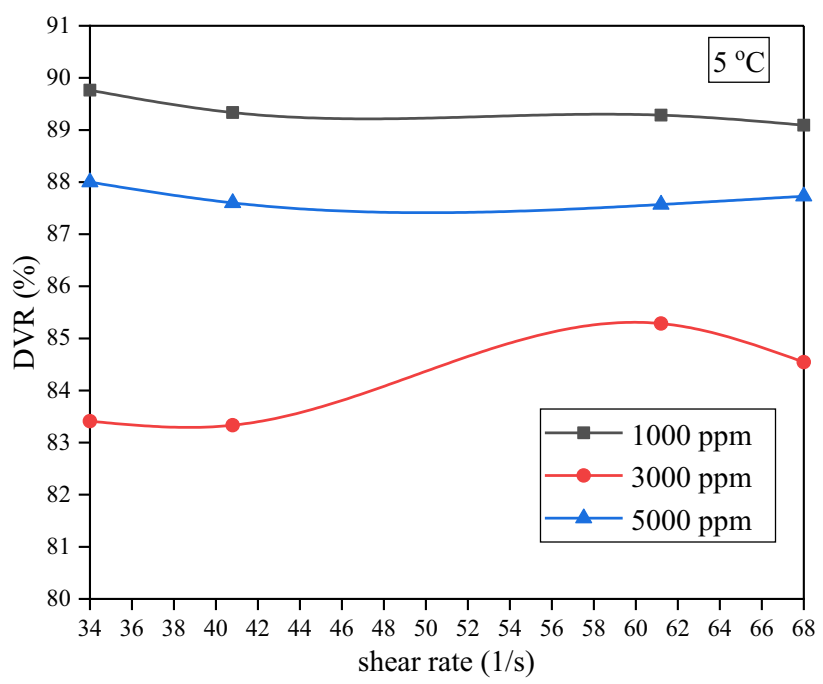

Fig. 10 Effect of shear rate on the DVR of treated crude oil at $5{ }^{\circ} \mathrm{C}$
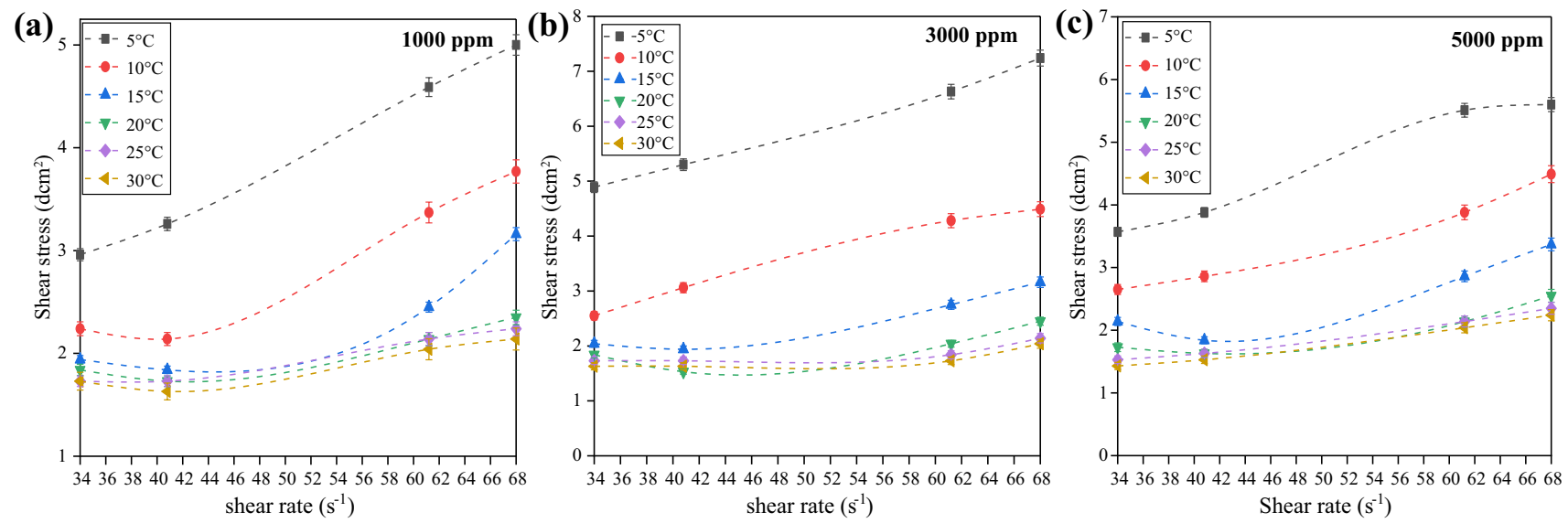

Fig. 9 Effect of shear rate on the shear stress of treated crude oil by concentrations of SA-co-BA PPD, (a) 1000 ppm, (b) 3000 ppm and (c) $5000 \mathrm{ppm}$ 
temperatures. For instance, DVR has been obtained in the same concentration at $30{ }^{\circ} \mathrm{C}$ by $31.8 \%$. It was concluded that DVR continues to increases as crude oil temperature decrease, particularly at temperatures more than the WAT.

The most essential and efficient viscosity reduction of the prepared SA-co-BA PPD was noted at $1000 \mathrm{ppm}$ and $5000 \mathrm{ppm}$ at $5{ }^{\circ} \mathrm{C}$, which showed the best performance of the DVR from $89.71 \%$ to $89.05 \%$, respectively. In contrast, the minimum DVR has exhibited at a concentration of $3000 \mathrm{ppm}$ by $83.41 \%$ at the same temperature.

\section{Effect of SABA copolymer as additives on wax deposition}

The amount of wax deposits formed using five different mass ratios of SA-co-BA copolymer at fixed concentration 1000 ppm is shown in Fig. 11a. The mass ratio of (1:1) of SA-co-BA copolymer PPD at $1000 \mathrm{ppm}$ was effective as the inhibitor on the pour point depression and viscosity reduction of crude oil, which may lead to reduction in the wax deposition. In this study, the amount of wax deposits of the untreated fluid was compared to the amount of wax deposits of treated crude oils by various mass ratio at a concentration of $1000 \mathrm{ppm}$. The amount of wax deposits of blank crude oil was $1.11 \mathrm{~g}$, compared with amount of wax deposits of treated crude oil, which is successfully decreased to 0.62 , $0.63,0.65,0.72$ and $0.67 \mathrm{~g}$. Note that in Fig. $11 \mathrm{~b}$, the PIE scale fell from $100 \%$ to $44.14 \%, 42.9 \%, 42.9 \%, 34.83 \%$ and $39.33 \%$ with a mass ratio (wt $\%)$ of $1: 1,2: 1,3: 1,1: 2$ and 1:3, respectively. The highest PIE was obtained at $1: 1$ of

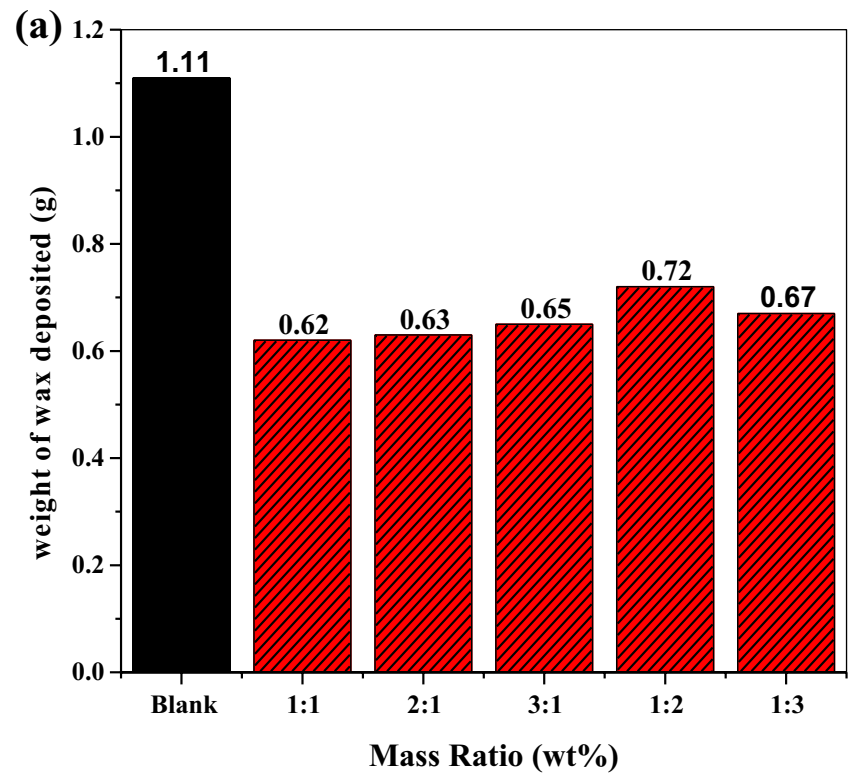

the mass ratio by $44.14 \%$, indicating the smallest amount of wax is formed.

These findings have demonstrated that the addition of SA-co-BA copolymer at a mass ratio (1:1) at $1000 \mathrm{ppm}$ can prevent the tube surface's wax formation growth and control the rigidity, adhesive ability and change the crystal structure itself. It is established that all mass ratios of the SA$c o$-BA copolymer utilized in this study have reduced wax deposition at a wide scale. It is believed that wax inhibitor interferes with wax growth and crystallization, reducing the amount of wax deposit (Theyab and Diaz 2016).

\section{Interaction mechanisms of pour point depressants with wax crystals}

The neighboring atoms in the wax molecules revolve around the $\mathrm{C}-\mathrm{C}$ single bond in the crude oil, maintaining a steady thermal motion. The inclusion of SA-co-BA PPD helps to minimize wax molecule motion order as well as the interaction force between them.

When the temperature is close to or below the WAT, wax inhibitors either co-crystallize with wax molecules or incorporate on the growing surface of precipitated wax crystals by adsorbed on the surfaces, as shown in Fig. 12. The SAco-BA PPD copolymer affects the wax crystal structure and aggregation state by interfering with the crystallization process. (Li et al. 2018; Sivakumar et al. 2018). The copolymer inhibitor's structure is comparable to that of wax molecules in some ways. Because of their similarities, the molecules are able to interact with wax crystals during crystal development. The structure, which is dissimilar to that of a wax

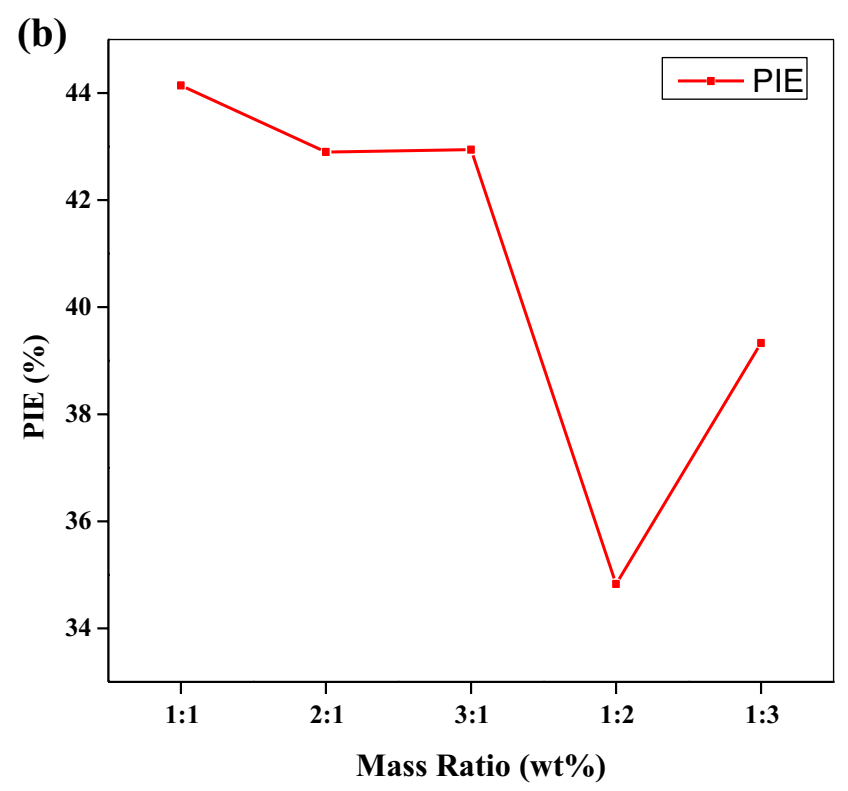

Fig. 11 The effect of SA-co-BA copolymer at various mass ratio on (a) weight of wax deposit, (b) the PIE\% 


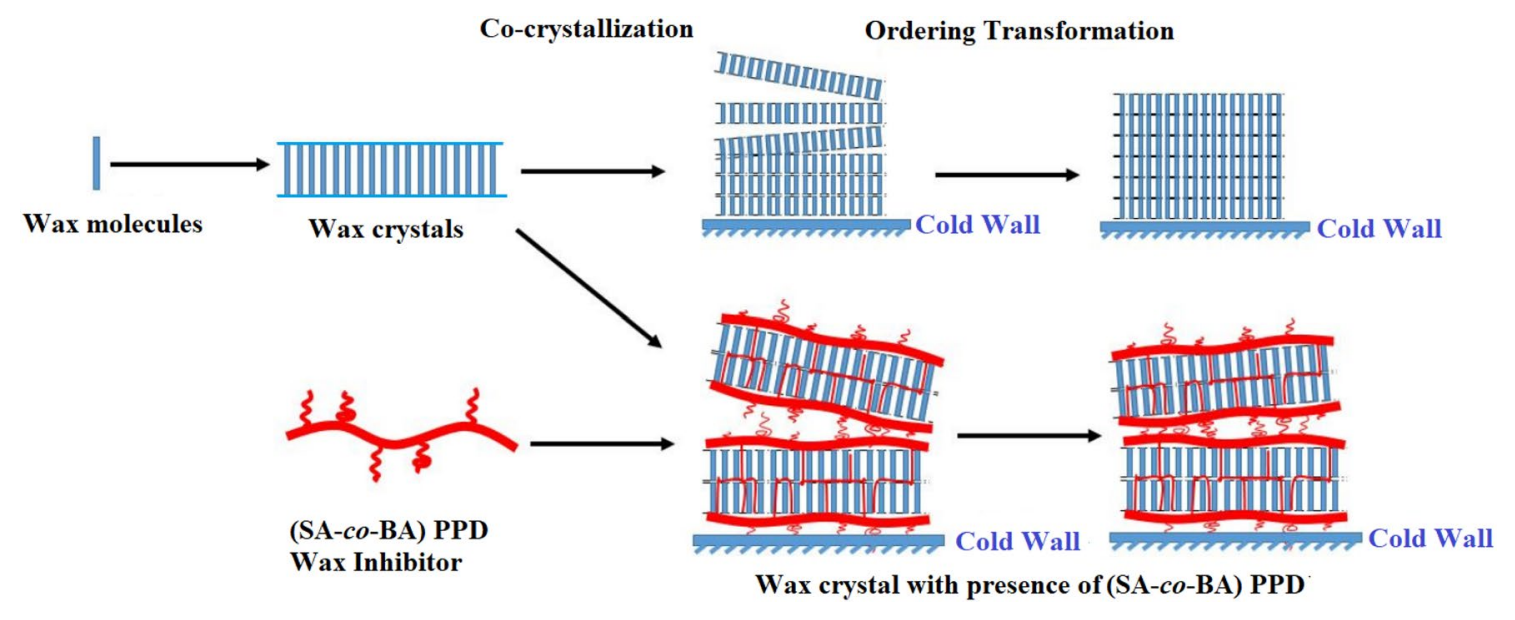

Fig. 12 Schematic representation of co-crystallization mechanism

crystal, is what prevents and disrupts crystal formation. This permits the weakened wax deposits to be sloughed off by the flow (drag) forces. They can also make the deposit weaker by limiting effective integration of wax crystals into the deposit. This permits the weakened wax deposits to be sloughed off by the flow (drag) forces. (Chi et al. 2019). According to Jang et al. (2007), in comparison to the pure system, the introduction of an inhibitor reduces the cohesive energy density (driving force for ordering change) by three times. As a result, the inhibitor slows down the growth and agglomeration of wax crystals (Chi et al. 2019).

\section{Conclusion}

The synthetization, characterization and evaluation of SA-co-BA copolymers as a novel PPD were investigated to improve the flowability and reduce the wax deposition of Malaysian crude oil at the lowest temperature. All results indicated that the copolymer samples at different mass ratios were successfully synthesized. The characterization results discovered that FTIR spectra characteristics had exhibited the highest absorption peaks at $2848.09 \mathrm{~cm}-1$ and $2914.86 \mathrm{~cm}-1$ which belong to - $\mathrm{CH} 2-$ and $\mathrm{CH} 3$ - groups, respectively. The NMR characteristic showed the double bond peaks $(\mathrm{C}=\mathrm{C})$ located between 5.59, 6.05, and $6.27 \mathrm{ppm}$ disappeared as expected. The XRD showed a severe diffraction peak at $2 \theta=21.5^{\circ}$, which belongs to the scattering crystalline phase of copolymer. Simultaneously, the SEM of the SA-co-BA copolymer surface has shown many folds that are stacked together irregularly. On the other hand, by comparing the efficiency of viscosity reduction to oil, addition of SA-co-BA copolymer to fluid sample results in a viscosity reduction at a reasonable level. Results recorded that the mass ratio (1:1) at $1000 \mathrm{ppm}$ exhibited a positive effect on the pour point depression of the waxy crude oil from 11 to $2{ }^{\circ} \mathrm{C}$. In addition, crude oil treated with the lowest concentration at $1000 \mathrm{ppm}(1: 1)$ showed the most efficient reduction of viscosity by $89.76 \%$, and the highest PIE was obtained at $1000 \mathrm{ppm}(1: 1)$ with $44.14 \%$. The effect of (SA-co-BA) PPD copolymer has an essential impact on the viscosity reduction due to the acrylate groups, which belong to a long alkyl chain of molecular weight and highest polydispersity. Consequently, SA-co-BA PPD copolymer was used as a multi functions for pour point depression, improving the crude oil flowability and reducing wax deposition.

Acknowledgements The authors would like to thank the Universiti Malaysia Pahang for laboratory facilities as well as additional financial support under internal research grant with reference code (RDU200302). We also thank to Petronas Penapisan Terengganu, Malaysia for providing crude oil samples for research project.

Funding This research was funded by University Malaysia Pahang through RDU200302 scheme.

\section{Declarations}

Conflict of interest The authors declare that they have no conflict of interest.

Open Access This article is licensed under a Creative Commons Attribution 4.0 International License, which permits use, sharing, adaptation, distribution and reproduction in any medium or format, as long as you give appropriate credit to the original author(s) and the source, provide a link to the Creative Commons licence, and indicate if changes were made. The images or other third party material in this article are included in the article's Creative Commons licence, unless indicated otherwise in a credit line to the material. If material is not included in the article's Creative Commons licence and your intended use is not permitted by statutory regulation or exceeds the permitted use, you will need to obtain permission directly from the copyright holder. To view a copy of this licence, visit http://creativecommons.org/licenses/by/4.0/. 


\section{References}

Akhil A, Koya M, Akhilesh S, Ashif M, Khan S, Kanna R (2017) Determination of cloud and pour point of various petroleum products. Int Ref J Eng Sci (IRJES) 6(9):1-4

Al-Sabagh A, El-Din MN, Morsi R, Elsabee M (2009) Styrene-maleic anhydride copolymer esters as flow improvers of waxy crude oil. J Petrol Sci Eng 65(3-4):139-146

Al-Sabagh A, Betiha M, Osman D, Hashim A, El-Sukkary M, Mahmoud T (2016) Preparation and evaluation of poly (methyl methacrylate)-graphene oxide nanohybrid polymers as pour point depressants and flow improvers for waxy crude oil. Energy Fuels 30(9):7610-7621

Al-Sabagh A, Khidr T, Moustafa H, Mishrif M, Al-Damasy M (2017) Synergistic effect between surfactants and polyacrylatesmaleicanhydride copolymers to improve the flow properties of waxy crude oil. J Dispers Sci Technol 38(7):1055-1062

Chen F, Liu J, Yang T, Yin S, Su B, Xie M, Xue Y (2020) Influence of maleic anhydride-co-methyl benzyl acrylate copolymers modified with long-chain fatty amine and long-chain fatty alcohol on the cold flow properties of diesel fuel. Fuel 268:117392

Chi Y, Daraboina N, Sarica C (2016) Investigation of inhibitors efficacy in wax deposition mitigation using a laboratory scale flow loop. AIChE J 62(11):4131-4139

Chi Y, Yang J, Sarica C, Daraboina N (2019) A critical review of controlling paraffin deposition in production lines using chemicals. Energy Fuels 33(4):2797-2809

Darvishi A, Zohuriaan Mehr MJ, Marandi GB, Kabiri K, Bouhendi H, Bakhshi H (2013) Copolymers of glycidyl methacrylate and octadecyl acrylate: synthesis, characterization, swelling properties, and reactivity ratios. Desig Mono Polym 16(1):79-88

Deka B, Sharma R, Mandal A, Mahto V (2018) Synthesis and evaluation of oleic acid based polymeric additive as pour point depressant to improve flow properties of Indian waxy crude oil. J Petrol Sci Eng 170:105-111

Deka B, Sharma R, Mahto V (2020) Synthesis and performance evaluation of poly (fatty esters-co-succinic anhydride) as pour point depressants for waxy crude oils. J Petrol Sci Eng 191:107153

Doguscu DK, Alkan C (2015) Synthesis of high molecular weight polystearylacrylate and polystearylmethacrylate polymers via ATRP method as thermal energy storage materials. Int J Eng Appl Sci 2(4):257962

Du T, Wang S, Liu H, Song C, Nie Y (2012) The synthesis and characterization of methacrylic acid ester-maleic anhydride copolymer as a lube oil pour point depressant. Petrol Sci Technol 30(2):212-221

Elarbe B, Ridzuan N, Yusoh K, Elganidi I, Abdullah N (2019) Screening of the factors for novel pour point depressant copolymer synthesis to improve the copolymer yield. In: Paper presented at the IOP Conference Series: Mater Sci Eng.

Elarbe B, Elganidi I, Ridzuan N, Abdullah N, Yusoh K (2021) Influence of poly (stearyl acrylate co-behenyl acrylate) as flow improvers on the viscosity reduction of Malaysian crude oil. Mater Today Proc 42(1):201-210

Elganidi I, Elarbe B, Abdullah N, Ridzuan N (2020) Synthesis of a novel terpolymer of (BA-co-SMA-co-MA) as pour point depressants to improve the flowability of the Malaysian crude oil. Mater Today Proc 42(1):28-32

Feng L, Zhang Z, Wang F, Wang T, Yang S (2014) Synthesis and evaluation of alkyl acrylate-vinyl acetate-maleic anhydride terpolymers as cold flow improvers for diesel fuel. Fuel Proc Technol 118:42-48

Geest C, Melchuna A, Bizarre L, Bannwart AC, Guersoni VC (2021) Critical review on wax deposition in single-phase flow. Fuel 293:120358
Ghosh P, Hoque M, Karmakar G, Das MK (2017) Dodecyl methacrylate and vinyl acetate copolymers as viscosity modifier and pour point depressant for lubricating oil. Int J Indus Chem 8(2):197-205

Goswami PK, Kashyap M, Das PP, Saikia PJ, Handique JG (2019) Poly (Glycidyl Methacrylate-co-Octadecyl Methacrylate) particles by dispersion radical copolymerization. J Dispers Scie Technol 41:1768-1776

Handayani D, Rachma A, Marliyana S (2019) Synthesis of copoly(eugenol-stearyl acrylate) via cationic polymerization. Paper presented at the J Physics 1153.

Hao LZ, Al-Salim HS, Ridzuan N (2019) A review of the mechanism and role of wax inhibitors in the wax deposition and precipitation. Pertanika J Sci Technol 27(1):499-526

Huda MK, Das PP, Saikia PJ, Baruah SD (2017) Synthesis of poly (n-octadecyl methacrylate-co-2-hydroxyethyl methacrylate) copolymer and their utilization as polymeric stabilizer in the preparation of PCL microspheres. Polym Bull 74(5):1661-1676

Jang YH, Blanco M, Creek J, Tang Y, Goddard WA (2007) Wax inhibition by comb-like polymers: support of the incorporation- perturbation mechanism from molecular dynamics simulations. J Phys Chem B 111(46):13173-13179

Khidr T, Doheim M, El-Shamy O (2015) Effect of ethoxylate on pour point depressant of fuel oil. Energy Sources Part A Recovery Utiliz Environ Effects 37(15):1697-1703

Kumar R, Bora GS, Banerjee S, Mandal A, Naiya TK (2018) Application of naturally extracted surfactant from Madhuca longifolia to improve the flow properties of heavy crude oil through horizontal pipeline. J Petrol Sci Eng 168:178-189

Li N, Mao G, Shi X, Tian S, Liu Y (2018) Advances in the research of polymeric pour point depressant for waxy crude oil. J Dispers Sci Technol 39(8):1165-1171

Litvinets IV, Prozorova IV, Yudina NV, Kazantsev OA, Sivokhin AP (2016) Effect of ammonium-containing polyalkyl acrylate on the rheological properties of crude oils with different ratio of resins and waxes. J Petrol Sci Eng 146:96-102

Machado AL, Lucas EF, González G (2001) Poly (ethylene-co-vinyl acetate)(EVA) as wax inhibitor of a Brazilian crude oil: oil viscosity, pour point and phase behavior of organic solutions. J Petrol Sci Eng 32(2-4):159-165

Odutola TO, Idemili CA (2020) Effect of poly (ethylene-butene) and nano-aluminium oxide blend on the viscosity of Nigerian crude oil. J Petrol Explor Prod Technol 10(6):2531-2539

Ridzuan N, Al-Mahfadi M (2017) Evaluation on the effects of wax inhibitor and optimization of operating parameters for wax deposition in Malaysian crude oil. Pet Sci Technol 35(20):1945-1950

Ridzuan N, Adam F, Yaacob Z (2016) Screening of factor influencing wax deposition using full factorial experimental design. Pet Sci Technol 34(1):84-90

Ridzuan N, Azhar A, Subramanie P (2020a) Evaluation on the factors influencing the deposition of wax using full factorial design. MS\&E 736(2):022023

Ridzuan N, Subramanie P, Elarbe B, Elganidi I, Kumar S (2020b) Screening and interaction study of the operating parameter influence the wax formation using design of experiment. MS\&E 736(2):022116

Rodbari RJ, Wendelbo R, Jamshidi LCLA, Hernández EP, Nascimento L (2016) Study of physical and chemical characterization of nanocomposite polystyrene/graphene oxide high acidity can be applied in thin films. J Chilean Chem Soci 61(3):3120-3124

Sarmah D, Baruah SD (2003) Synthesis, characterization, and thermal properties of copolymers of behenyl acrylate and behenyl fumarate. J Appl Polym Sci 90(10):2721-2726 
Senra M, Panacharoensawad E, Kraiwattanawong K, Singh P, Fogler HS (2008) Role of n-alkane polydispersity on the crystallization of n-alkanes from solution. Energy Fuels 22(1):545-555

Sharma R, Mahto V, Vuthaluru H (2019) Synthesis of PMMA/modified graphene oxide nanocomposite pour point depressant and its effect on the flow properties of Indian waxy crude oil. Fuel 235:1245-1259

Sharma R, Kautish P, Kumar DS (2021) Assessing dynamism of crude oil demand in middle-income countries of South Asia: a panel data investigation. Glob Bus Rev 22(1):169-183

Sivakumar P, Sircar A, Deka B, Anumegalai AS, Moorthi PS, Yasvanthrajan N (2018) Flow improvers for assured flow of crude oil in midstream pipeline-A review. J Petrol Sci Eng 164:24-30

Soliman EA, Elkatory MR, Hashem AI, Ibrahim HS (2018) Synthesis and performance of maleic anhydride copolymers with alkyl linoleate or tetra-esters as pour point depressants for waxy crude oil. Fuel 211:535-547

Souas F, Safri A, Benmounah A (2020) A review on the rheology of heavy crude oil for pipeline transportation. Petrol Res 6(2):116-136

Subramanie PA, Padhi A, Ridzuan N, Adam F (2020) Experimental study on the effect of wax inhibitor and nanoparticles on rheology of Malaysian crude oil. J King Saud Univ-Eng Sci 32(8):479-483

Taborda EA, Franco CA, Lopera SH, Alvarado V, Cortés FB (2016) Effect of nanoparticles/nanofluids on the rheology of heavy crude oil and its mobility on porous media at reservoir conditions. Fuel 184:222-232

Theyab MA, Diaz P (2016) Experimental Study on the effect of inhibitors on wax deposition. J Petrol Enviro Biotechnol 7:1-5

Tu Z, Jing G, Sun Z, Zhen Z, Li W (2017) Effect of nanocomposite of attapulgite/EVA on flow behavior and wax crystallization of model oil. J Dispers Sci Technol 39(9):1280-1284

Xie M, Chen F, Liu J, Yang T, Yin S, Lin H, Han S (2019) Synthesis and evaluation of benzyl methacrylate-methacrylate copolymers as pour point depressant in diesel fuel. Fuel 255:115880

Xu J, Xing S, Qian H, Chen S, Wei X, Zhan R, Guo X (2013) Effect of polar/nonpolar groups in comb-type copolymers on cold flowability and paraffin crystallization of waxy oils. Fuel 103:600-605

Xu G, Xue Y, Zhao Z, Lian X, Lin H, Han S (2018) Influence of poly (methacrylate-co-maleic anhydride) pour point depressant with various pendants on low-temperature flowability of diesel fuel. Fuel 216:898-907
Yang F, Paso K, Norrman J, Li C, Oschmann H, Sjöblom J (2015a) Hydrophilic nanoparticles facilitate wax inhibition. Energy Fuels 29(3):1368-1374

Yang F, Zhao Y, Sjöblom J, Li C, Paso KG (2015b) Polymeric wax inhibitors and pour point depressants for waxy crude oils: a critical review. J Dispers Sci Technol 36(2):213-225

Yang F, Yao B, Li C, Shi X, Sun G, Ma X (2017) Performance improvement of the ethylene-vinyl acetate copolymer (EVA) pour point depressant by small dosages of the polymethylsilsesquioxane (PMSQ) microsphere: An experimental study. Fuel 207:204-213

Yang F, Cheng L, Liu H, Yao B, Li C, Sun G, Zhao Y (2018) Comblike polyoctadecyl acrylate (POA) wax inhibitor triggers the formation of heterogeneous waxy oil gel deposits in a cylindrical couette device. Energy Fuels 32(1):373-383

Yao B, Li C, Zhang X, Yang F, Sun G, Zhao Y (2018) Performance improvement of the ethylene-vinyl acetate copolymer (EVA) pour point depressant by small dosage of the amino-functionalized polymethylsilsesquioxane (PAMSQ) microsphere. Fuel 220:167-176

Zhang X, Yang F, Yao B, Li C, Liu D, Sun G (2020) Synergistic effect of asphaltenes and octadecyl acrylate-maleic anhydride copolymers modified by aromatic pendants on the flow behavior of model waxy oils. Fuel 260:116381

Zhao Z, Yan S, Lian J, Chang W, Xue Y, He Z, Han S (2018) A new kind of nanohybrid poly (tetradecyl methyl-acrylate)-graphene oxide as pour point depressant to evaluate the cold flow properties and exhaust gas emissions of diesel fuels. Fuel 216:818-825

Zhu X, Gu Y, Chen G, Cheng Z, Lu J (2004) Synthesis of poly (octadecyl acrylate-b-styrene-b-octadecyl acrylate) triblock copolymer by atom transfer radical polymerization. J Appl Polym Sci 93(4): 1539-1545

Zhu L, Wang S, Huang C, Tian Y, Yang X, Jing X, Li A (2018) Screening of Synthesis Conditions of Polymers and the Effects on Viscosity Reduction Performance. In: Paper presented at the IOP Conference Series: Ear Enviro Sci.

Publisher's Note Springer Nature remains neutral with regard to jurisdictional claims in published maps and institutional affiliations. 